Verb-based vs. schema-based constructions and their variability On the Spanish transitive directed motion construction in a contrastive perspective Pedersen, Johan

Published in:

Linguistics

Publication date:

2019

Document version

Publisher's PDF, also known as Version of record

Citation for published version (APA):

Pedersen, J. (2019). Verb-based vs. schema-based constructions and their variability: On the Spanish transitive directed motion construction in a contrastive perspective. Linguistics, 57(3), 473-530. 
Johan Pedersen*

\title{
Verb-based vs. schema-based constructions and their variability: On the Spanish transitive directed-motion construction in a contrastive perspective
}

\author{
https://doi.org/10.1515/ling-2019-0007
}

Abstract: In comparison to English, Spanish constructions of argument structure are highly verb-constrained (e.g., Goldberg, Adele E. 2006. Constructions at work: The nature of generalization in language. Oxford: Oxford University Press; Narasimhan, Bhuvana. 2003. Motion events and the lexicon: A case study of Hindi. Lingua 113(2). 123-160): Pedro bajó/*bailó a la playa 'Pedro went down/ danced to the beach'. In some cases, the dominant role of the verbal meaning combines with a mismatching construction (e.g., an intransitive verb in a transitive construction: Pedro bajó las escaleras 'Pedro went down the stairs'). To account for this evidence from a usage-based point of view, this study examines the Spanish transitive directed-motion construction combining verb lexeme analysis with collexeme corpus analysis (Stefanowitsch, Anatol \& Stefan Th. Gries. 2003. Collostructions: Investigating the interaction beween words and constructions. International Journal of Corpus Linguistics 8(2). 209-243). The analysis shows that in spite of frequent verb-construction mismatches, core components of the verbal meaning correlate closely with the usage of the verb in the transitive construction. The same patterns were not observed in comparable English constructions. Conceptualized in a constructionist framework, this study suggests that verb framing and learned constructional patterns have different roles in the encoding of argument structure in the two languages. This contrastive analysis has a broader application: to other construction types, to other semantic domains, and to other languages. It is argued that compared to the typological distinction between Verbframed and Satellite-framed languages (Talmy, Leonard. 2000. Toward a cognitive semantics, vol. 1 and 2. Cambridge, MA: MIT Press), the proposed framework is better suited to account for the crosslinguistic differences and the intra-linguistic variation.

*Corresponding author: Johan Pedersen, Department of English, Germanic and Romance Studies, University of Copenhagen, Emil Holms Kanal 6, DK-2300 Copenhagen, Denmark, E-mail: jhp@hum.ku.dk 
Keywords: constructions, verb framing, argument structure constructions, Spanish, transitive directed motion, typology

\section{Introduction}

Spanish constructions of argument structure are verb-constrained to a much higher degree relative to Germanic languages (e.g., Goldberg 2006; Narasimhan 2003; Pedersen 2013; Talmy 1991, Talmy 2000; Snyder 2001; Levin and Rappaport Hovav 2019; Martínez Vázquez 2001; among many others). In contrast to English, for instance, Spanish verbs show a strong tendency only to occur in constructional environments where the verbal predication matches the intended sentence meaning as seen in (1). Spanish verb-construction mismatch is usually not allowed, as exemplified in (2), in which a Spanish atelic Manner of motion verb (bailar 'to dance') is unsuccessfully used in a frequent construction of directed telic motion, cf. (1):

(1) Pedro baj-ó a la playa.

Pedro move down-PST.3SG to the beach

'Pedro went down to the beach.'

(2) `Pedro bail-ó a la playa.

Pedro dance-PST.3SG to the beach

'Pedro danced to the beach.'

From a constructionist point of view, users generalize about frequent usage, forming abstract and verb-independent argument structure constructions (Goldberg 1995, Goldberg 2006). The argument structure construction provides constructional meaning, which is available for constructional coercion of mismatching verbs. The grammatical English version of (2) exemplifies such a potential mismatch in English. The crucial issue here is that if argument structure constructions are formed via generalizations in the minds of English users, this is probably also the case in the minds of Spanish users. As Goldberg puts it:

Verbs in many languages are more restrictive than they are in English, only appearing in constructions that match their meanings, ..., And yet it seems unlikely that they fail to form argument structure constructions in such languages [e.g., Spanish, other Romance languages, Turkish, Hindi]. (Goldberg 2006: 120)

Thus, verb-construction mismatch should also be available in Spanish, ceteris paribus. In fact, specific types of verb-construction incongruence can also be 
observed in Spanish (e.g., Bosque 2009: Sections 34.5-34.7; Gonzálvez-García 2009), particularly in simple transitive constructions:

(3) Pedro bajó

las escaleras. (Spanish, intransitive Path verb) Pedro move down-PST.3SG the stairs

'Pedro went down the stairs.'

Nevertheless, as in (1), (3) is also verb constrained in the sense that the core meaning (directed motion) is provided by the intransitive verb. In this case, the argument structure construction is a transitive construction, which is incongruent with the core meaning of the intransitive verb. This has significant and intriguing implications for a constructionist approach to Spanish argument structure. It suggests that the role of Spanish argument structure constructions differs from the role argument structure constructions arguably have in English in providing a skeleton of the sentence meaning (Goldberg 1995). The question is, what is the role of constructional meaning in argument structure when, as seems to be largely the case in Spanish, information about the meaning skeleton is provided by the verb? To answer this question we need a framework that, on the one hand, accounts for the characteristic failure of complex constructions with incongruent verb-construction meaning, as exemplified in (2). On the other hand, it should also be able to account for the grammaticality of simple transitive constructions with verb-construction incongruence, as exemplified in (3).

In Talmy's typological framework, expressions of directed motion in Romance languages, including Spanish, lexicalize the path/main event by the verb (so-called "verb(V)-framed languages"), and may express the manner/co-event outside the verb, typically by adding a gerund or an adverbial. Germanic languages, in contrast, lexicalize the path/main event in a satellite (so-called "satellite(S) framed languages”), and the manner/co-event by the verb (e.g., Talmy 1991, Talmy 2000). ${ }^{1}$ The Spanish examples in (1)-(3) are clearly accounted for in this typological framework. When comparing the Spanish constructions to English parallel constructions, Talmy's typology should account for the crosslinguistic differences. However, since the transitive surface form is the same in the two languages, the notion satellite does not suit the transitive construction of directed motion. Moreover, both Path verbs and Manner verbs occur regularly in this construction in both languages (cf. [3]):
(4) Fernando salt-ó
la valla.
(Spanish, Manner verb)
Fernando jump-PST.3SG the fence
'Fernando jumped over the fence.'

1 For elaborations of the typological framework, see, e.g., Slobin (2004), among many others. 
Thus, the lexicalization of path/manner and main event/co-event is not typologically distinctive. In short, Talmy's V-framed vs S-framed distinction is not appropriate to account for crosslinguistic differences in the transitive construction. The basic idea in the present study is that, as an alternative conceptual framework, the role of different layers of encoded meaning (verbal meaning vs constructional meaning) may be typologically distinctive.

From a constructionist point of view, categorizations - syntactic as well as semantic - should preferably be made for a specific, well-defined constructional environment; categories (e.g., objects or object roles) are construction specific and constructions are language specific (Croft 2001; Croft et al. 2010). Spanish constructions of directed motion can be roughly divided into three variants:

(7) Fernando se fue a-l otro

Fernando REFL go-PST.3SG to-the other

lado de...

Intransitive directed motion

side of

'Fernando went to the other side of ...'

(8) Fernando cruz-ó la calle. Transitive directed motion (TDM) ${ }^{2}$ Fernando cross-PST.3SG the street

'Fernando crossed the street.'

(9) Fernando met-ió la pelota

Fernando place-PST.3SG the ball

en la caja.

Transitive caused (directed) motion

in the box

'Fernando placed the ball in the box.'

This article presents the results from a large-scale quantitative corpus study of what I refer to as the Spanish TDM construction. Since the TDM construction shows evidence of verb-construction incongruence (see example (3) and [4]), it is a particularly interesting case for the study of the role of verb meaning and constructional meaning in constructions of Spanish argument structure.

2 Some linguists refer to a group of verbs that govern locative objects; see, e.g., Demonte (1990); Cano Aguilar (1981); García Miguel (1995); Campos (1999: 1534). 
In the next section (Section 2), I briefly discuss the characteristics of the TDM construction with focus on the notions transitivity and transitive construction. Section 3 provides the theoretical framework. Section 4 describes the methodology used in a large corpus study of the Spanish TDM construction. In Section 5, I analyze the data and present the results. In Section 6, I discuss the results in a crosslinguistic perspective, contrasting the Spanish data with comparable evidence from English. Finally, I discuss the interpretation of the results in relation to Talmy's typological framework. Section 7 is the conclusion. The appendix is a complete list of verb-TDM construction association data.

\section{The TDM construction and transitivity}

Transitivity has been defined in a number of different ways, depending on the theoretical framework and the aspect of transitivity focused on (e.g., Kittilä 2002, Kittilä 2011; Næss 2007). Since the present study is based on a constructionist understanding of grammatical units as form-meaning pairings, a two-sided interdependent formal-semantic understanding of transitivity is crucial. In general terms, transitivity involves formal and semantic properties associated with the encoding of basic events. Langacker defines the transitive event in highly abstract conceptual terms as a transfer of energy among entities X and Y (participants/arguments) of basic events: 'X transfers energy to Y' (see Langacker 1991: 285). Prototypically, a human agent targets its action at an affected patient (e.g., Dowty 1991; Givón 1995: 76; Hopper and Thompson 1980: 252). Marginally, the transitive event is a family of related transitive meanings associated with this prototype (e.g., Goldberg 1995: 116-119; Hopper and Thompson 1980; Rice 1987). The transitive event is usually encoded as a direct object relation by means of verbs that take a direct object, or accusative case marking. As a direct implication of the constructionist notion construction specific categories (cf. Croft 2001), we should not expect the transitivity of the TDM-construction to be prototypical because of its specific properties. This is relevant for our understanding of verbal transitivity and the specific direct object type in the spatial domain of the TDM construction (see Section 2.2). As I will show in the next section, in the internal structure of the TDM construction the specific contribution of verbal versus constructional transitivity plays an important role.

\subsection{On determining transitivity in the data}

Transitivity may be associated with verbal properties as well as constructional properties. Moreover, it is a scalar phenomenon in the sense that it does not 
imply a binary dichotomy of intransitive and transitive events (e.g., Hopper and Thompson 1980; Givón 1995). Nevertheless, it is useful to be able to distinguish between intransitive and transitive verbs/constructions; or at least high versus low verbal/constructional transitivity. In the present study, I determine transitivity as a gradable property of verbs and constructions.

If a language has a structural opposition between active and passive voice, we may say that the possibility of showing this opposition depends on a semantic property of the verb, its transitivity (Luraghi 2010). Conversely, a successful passive shift from active to passive voice is a characteristic syntactic manifestation of this verbal property (e.g., Kulikov 2011: 270-72; Luraghi 2010; among many others). Thus, we may use passivization of a simple two-argument construction as an indicator of high/low (no) transitivity of a specific verb. In addition, we may identify transitivity in terms of constructions with a direct object, or an object in the accusative case (e.g., Kittilä 2011: 347-48; Lazard 1998: 160). Syntactic operations such as the passive shift and the case marker substitution in a simple two-argument construction may be used as diagnostics to distinguish between (1) high/low (no) transitivity of verbs (passive shift) and (2) transitivity of the TDM construction (case marker substitution).

Unlike the passive shift, the case marker substitution does not manipulate the argument structure of the basic event in which the verb is involved. Thus, while the latter operation is an indication of transitivity in the TDM construction, it is not necessarily an indication of verbal transitivity in the internal structure of the TDM construction. In short, this diagnostics may determine the use of intransitive verbs in transitive constructions: Pedro bajó las escaleras 'Pedro went down the stairs' $\rightarrow$ Pedro las bajó 'Pedro ACC went down', but *las escaleras fueron bajadas por Pedro 'the stairs were gone down by Pedro'.

\subsection{The TDM-construction}

When a motion verb combines with a direct object in the TDM construction, the role of the latter is not 'the affected patient' as it is in the prototypical transitive construction. It is a location. Givón (1984: 96-99) explained the English expression of transitive directed motion as a deviation from prototypical transitivity by constructing a locative entity (metaphorically) as a patient object:

\section{Peter entered the room}

He argued that the locative argument accedes to objecthood whenever it undergoes affectedness, understood in a wider sense. Tenny's work is an interesting 
contribution to the understanding of this specific transitive construction. According to Tenny (1995), transitive directed motion typically provides a scale to measure the process of the motion event in terms of spatial entities:

(11) Mary paddled the Allegheny River

(Tenny 1995: 51)

In this understanding of transitive motion, the role of the TDM object reflects a homomorphism of spatial objects to events (cf. Krifka 1992; Tenny 1995). Spatial objects behave like patient objects in the sense that they measure a property (the path of motion) of the event.

Tenny's approach differs fundamentally from Givón's early analysis, but the two converge in some aspects. For instance, some English expressions of transitive motion such as walking the hills of Scotland (Tenny 1995) are understood as a kind of act of consumption, where all the hills are walked over until they have all been walked over (cf. figurative affectedness and the affected/consumed patient in Givón 1984). According to Tenny (1995), this interpretation makes the bounded reading possible in spite of the unbounded semantic profile of Manner verbs. Quantification can play a role here by emphasizing complete coverage of the object: walk all the hills of Scotland (Tenny 1995, note 33).

Inspired by Tenny's work, and based on studies of French and Korean, ChoiJonin and Sarda (forthcoming) suggest that some Path verbs may occur in the transitive construction because their meaning incorporates the semantic component 'region' that enriches the structure of the path. For more details on the French data, see Sarda $(1999,2000) .{ }^{3}$ Oliveira (2016) recently discussed the TDM construction with reference to Portuguese data, pointing out that the key element that characterizes a transitive directed-motion construction seems to be a schematic bounded path (= ground) encoded by the verb. While Japanese, like these languages, tends to be considered a verb-framed language with Motion and Path encoded by the verb, according to Muehleisen and Imai (1997) this characterization of Japanese should be reconsidered, since many Japanese Path verbs also contain specific information about the nature of the ground, i.e., the space traversed by the path. They suggested that Japanese Path verbs of this specific type have increased transitivity and qualify as 'Ground Path verbs'. Previously, Dubinsky (1985) discussed the transitivity of the Japanese TDM construction from the theoretical point of view of the Relational Grammar framework. He argued that the locative NPs associated with intransitive verbs have transitive properties in the construction. However, he argued, they do not

3 Melis (2001) discussed the transitivity of the French transitive directed-motion construction. 
behave as direct objects at all syntactic levels. In particular, they differ syntactically from the direct objects of transitive verbs. Since French, Portuguese, Korean and Japanese are verb-framed languages in Talmy's typological framework, and French and Portuguese are Romance languages like Spanish, it is reasonable to assume that similar patterns might apply to the Spanish case to some extent, e.g., (3), repeated here as $(12)^{4}$ :
Pedro baj-ó
la escalera
Pedro move down-PST.3SG the stairs
'Pedro ran down the stairs'

Inspired by the ideas in Tenny (1995), which have been adapted to a constructionist framework in the present study, I see the generalized meaning of the TDM construction as an elaboration of the path of motion in terms of traversing/ traversed distance in space. The homomorphism from the spatial domain to the process of the event, which, according to Tenny (1995), is part of the semantics of these expressions, predicts that the process of the event will have aspectual elements associated with elements of the space traversed (cf. Tenny 1995: 49). In general terms, what I refer to as the prototypical TDM construction provides, by means of a direct object relation, an elaboration of the path of motion in terms of traversing/traversed space:

TDM: X traverses space $\mathrm{Y}$

\section{The constructionist framework}

The theoretical foundation of this study is a constructionist framework. According to constructionist approaches to grammar, clausal information is organized in constructions, defined as pairings of form and meaning at different levels of specificity (e.g., Langacker 1987, Langacker 2009; Fillmore and Kay 1999; Croft 2001; Goldberg 2006, Goldberg 2009a; Goldberg and Jackendoff 2004). Constructions are interrelated and have properties inherited from other constructions. Importantly, what we refer to as a specific construction in the sense of a concrete expression type with a meaning content, for instance, the TDM construction, usually contains different construction types in its internal structure (e.g., argument structure constructions and lexeme constructions). It is

4 Korean is a verb-framed language, but it allows serial verb constructions and postpositional markers (Talmy 2000). 
a key issue in Goldberg's later work that constructions, including argument structure constructions, are learned from usage via surface generalizations (Goldberg 2006). Such generalizations proceed from a cognitive ability and relate closely to the principles of usage-based grammars (e.g., Langacker 1987, Langacker 1988, Langacker 1990, Langacker 2000; Kemmer and Barlow 2000; Tomasello 2003; Bybee 2007; Goldberg 2006; Verhagen 2002). These principles lead directly to the importance of frequency effects in the formation of grammar (e.g., Diessel 2007; Knobel et al. 2008; Stefanowitsch and Gries 2003; Bybee 2007). Frequencies of repeated linguistic processing events convert into different degrees of entrenchment (Langacker 1987) - understood as different strengths of association, degrees of automatization, and levels of cognitive effort required for processing - in the network that represents grammatical knowledge (Schmid 2007; Blumenthal-Dramé 2012).

As a theoretical notion, construction should not be confused with construal. All (subjective) choices of linguistic structure (construction) to encode clausal meaning impose a certain construal on the conceptual meaning it codes, which may involve focal adjustments (e.g., perspective), prominence structure (e.g., transitive versus intransitive construal), or level of specificity. Subparts of a construction may also provide a specific construal of its conceptual content. Conversely, the notion construal does not refer to the encoding of the core meaning of the clausal content; e.g., the event structure (see, e.g., Langacker 1987: 487-88, 1991: 294-98; Verhagen 2011). For a thorough discussion of construal phenomena in linguistics, see Verhagen (2011). ${ }^{5}$

The role of the argument structure construction (henceforth ASC) in the encoding of argument structure has been intensely discussed since Goldberg's work on generalization in language (Goldberg 2006, Goldberg 2009a, Goldberg 2009b), pioneered by Goldberg's earlier work on English ASCs (Goldberg 1995). The basic idea is that constructional meaning exists independently of the contribution to argument structure provided by the verbal predicate and its lexical participants. The principal elements of Goldberg's proposal are: (A) The ASC is a schematic encoding of argument structure that represents the meaning skeleton of the clause, e.g., [SUBJ V OBJ $\left.\mathrm{OBJ}_{2}\right] / \mathrm{S}^{\prime} \mathrm{X}$ causes $\mathrm{Y}$ to receive $\mathrm{Z}$ ' (the ditransitive ASC of 'transfer-meaning'). Arguments are ASC-roles (e.g., agent, patient or recipient). (B) In the internal structure of constructions, the ASC integrates with lexical items that substantiate the skeletal meaning with frame semantic information: Peter gave Mary a present (giving-frame) / John mailed Lucy the documents (mailing-frame). Participants are frame-semantic roles (e.g., giver,

5 For more details on the role of constructional meaning, see also Butler and Gonzálvez-Garcîa (2014), Gonzálvez-García and Butler (2006), and Ruiz de Mendoza (2013). 
given object, or recipient) in the predication provided by the verb lexeme (= verb framing). (C) The ASC is not predicted by the verb, but to a varying degree is motivated by the verb meaning, or merely compatible with the verb meaning (see Goldberg 1995: 25-31).

In constructionist approaches to grammar, transitivity is not a universal category; it is construction specific (Croft 2001: Ch. 1). An important implication of this is that, as with lexemes, the transitive argument structure construction (ASC) is polysemous: the same formal pattern ([SUBJ V OBJ]) may have various related transitive meanings (cf. Goldberg 1995: 31-39 and 116-119):

Prototypical transitive ASC:

Typical transitive ASC of the TDM construction:
[SUBJ V OBJ] / 'X affects Y'

[SUBJ V OBJ] / 'X traverses space Y'

In a crosslinguistic perspective, there is strong evidence for the privileged role of the verb in Spanish and typologically similar languages (e.g., Talmy 2000; Jackendoff 1983, Jackendoff 1990; Goldberg 2006: 120; Martínez Vázquez 2001; Narasimhan 2003; Pedersen 2013; Beavers et al. 2010; Croft et al. 2010; Snyder 2001; Levin and Rappaport Hovav 2019 and cited references therein). Talmy's influential lexicalist-oriented typology is based on form-meaning mapping in one single layer of encoding: lexicalization patterns (see Section 1). His framework does not capture the essential constructionist claim that the construction per se constitutes an independent contribution to clausal meaning that integrates with lexical meaning (cf. Goldberg 1995). For instance, while Spanish is verb-framed and does not usually allow verb-sentence meaning mismatch (e.g., Goldberg 2006; Pedersen 2013; cf. example [2]), verb-independent ASCs still seem to play a role in Spanish constructions of argument structure to account for cases of verb-construction mismatch (see, e.g., Goldberg 2006; GonzálvezGarcía 2009; Pedersen 2014).

Unexpected and mismatching combinations of the ASC and the verb lexeme in which the verb is 'non-congruent' with the construction it appears in (with constructional overriding of meaning), as in the successful English version of example (2), has been referred to as a specific kind of constructional coercion. For various definitions of this notion and more details, see, e.g., Pustejovsky (1991: 425), Pustejovsky (1995); Michaelis (2003a), Michaelis (2003b: 261), Michaelis (2004), Michaelis (2005), Taylor (2003: 589), de Swart (2000), Goldberg (1995), Moens and Steedman (1988), Croft (1991), Boas (2011), Panther and Thornburg (1999), Israel (1996), Hilpert (2008), Traugott (2007), Yoon (2012). Langacker (2009) uses the notion skewing. In constructionist 
approaches to argument structure, the notion coercion is largely used to account for specific - and often creative - usage in the grammar (see, e.g., the English version of example [2]). Conversely, evidence of coercion has been used as an argument for the existence of ASCs in the grammar (Goldberg 1995). When the clause meaning cannot be predicted from the verb meaning, this may be an indication that such information is provided as another, schematic, meaning layer in the grammar, independent of the contribution of the verb. Thus, we may consider the observation of coercion effects to be essential - and coercion a central notion - in the sense that it suggests that the ASC, not the verb, is the best overall predictor of sentence meaning. Some constructionist scholars have emphasized that this verb-independent role of learned patterns of argument structure should not be overestimated. They suggest that we should pay more attention to the constraints that individual senses of the verb impose on their fusion with constructional patterns, leading to detailed descriptions in terms of frame semantics (e.g., Boas 2003, Boas 2005, Boas 2010, Boas 2011, Boas 2013; Goldberg 2006: chap. 10, Goldberg 2013; Iwata 2008; Nemoto 2005; see also Ruiz de Mendoza and Mairal-Usón 2008).

To be able to capture principles of encoding in constructions of Spanish argument structure, first we need a constructionist framework that accounts for a broad array of frequent construction types in which verb-construction incongruence is not allowed. The intransitive directed-motion construction exemplified in (1) and (2) is just one example. The resultative construction is another example: *Pedro le habló fuera de la habitación 'Pedro talked him out of the room'. The English version is successful, arguably because the ASC provides the meaning skeleton by means of constructional coercion of the verb. The Spanish version seems to fail because the verb hablar 'to talk' cannot provide a meaning skeleton of the intended meaning (' $X$ caused $Y$ to move Z') and because constructional coercion of the verb apparently is not an encoding option. Thus, a framework that allows for constructional coercion of the verb in Spanish, would conflict with this overwhelming evidence of the privileged role of the verb in the Spanish sentence referred to above and in Section 1. Secondly, the framework has to account for some Spanish construction types in which verb-construction incongruence seems to occur regularly such as the TDM construction focused on in the present study and exemplified in (3)-(4). As we shall see, an accommodated notion of coercion is appropriate to describe the latter construction types: the verb dominance coerces the ASC into a secondary role. However, this adapted notion of lexical coercion is less suitable to describe the even stronger verb constraints on the former types, which represent the prototypical case in Spanish. This complexity suggests that while it is conceptually highly relevant, coercion should probably not be the central notion in a constructionist framework that accounts for the Spanish case. 


\subsection{The construction of argument structure - a developmental perspective}

A crucial issue that qualifies the debate about lexicalist versus constructionist approaches to grammar is children's early non-perfect ability to construct argument structure when they have not yet learned the general patterns of argument structure. Tomasello (1992) observed that children's early clausal constructions are commonly organized around particular verbs, such as give and throw, which they associate with specific unrelated structural patterns. More recently, Tomasello has characterized these early acquired constructions of argument structure as constructional islands (e.g., Tomasello 2002: 313). ${ }^{6}$ Later, children's constructions become increasingly more generalized and independent of particular lexical items. Two aspects of grammatical development are particularly relevant here: (1) generalizing the verb-productive competence and (2) generalizing beyond specific verbs to form abstract ASCs (Diessel 2013). First, the complement slots of the early item-based constructions become increasingly more flexible and schematic. This makes verb-based constructions gradually more productive: I wanna bag - I wanna ride (my horsie) - I want ice cream in the refrigerator - want me open it ... (Diessel 2004: 68-72). Children initially generalize at the level of specific verbs plus argument slots "because the verb plus argument frame is the best single word predictor of overall sentence meaning” (Goldberg 2006: 126). We may say that by generalizing from the early itembased constructions, children learn the strong predictability of the verb in what I refer to as verb frame constructions (VFC) (cf. Boas 2003). Technically, I will capture such early-acquired verb-based productive competence by suggesting the existence of a generic VFC in the grammar:

Generic VFC: [VERB $\mathrm{ARG}_{0} \ldots \mathrm{ARG}_{\mathrm{n}}$ ] / 'verb congruent meaning'

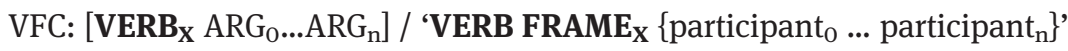

In construction grammar, rules (= generalizations) are captured and represented as abstract constructions, that is, schematic form-meaning pairings (see, e.g., Goldberg 2006: chap. 3, in particular, pp. 62-65). Accordingly, the generic VFC is a learned constructional rule that associates the general form of argument structure (verb + arguments) with 'verb congruent meaning'. It is a constructionist representation of a learned productive rule of verb framing. By knowing the

6 Cf. Braine’s (1976) characterization of early item-based constructions as pivot constructions. 
generic VFC, we have the ability to organize the encoding of clausal meaning by means of the verb. Concrete instances of verb framing (VFC) include all kinds of verbal predication in which the verb meaning is closely associated with a verbcongruent meaning, e.g., [eat SUBJ OBJ] / 'eating frame \{eater, food\}', as in Peter ate the sandwich. Participants (e.g., eater, food) are lexically profiled roles in the verb frame (Goldberg 1995: 43-59).

Following general principles of usage-based grammars (see Section 3) the generic VFC is assumed to be acquired as a generalization from usage in which frequent associations of specific verb types with congruent and predictable sentence meanings are experienced. Figure 1 illustrates an imagined scenario in which each of six verb types $\left(V_{n}\right)$ occurs with a token frequency of 10 , with one specific - congruent and predictable - sentence meaning $\left(C_{n}\right)$.

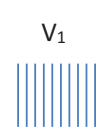

$\mathrm{C}_{1}$

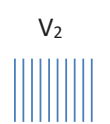

$\mathrm{C}_{2}$

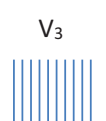

$\mathrm{C}_{3}$

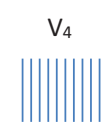

$\mathrm{C}_{4}$

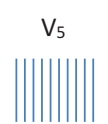

$\mathrm{C}_{5}$

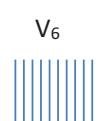

$\mathrm{C}_{6}$

Figure 1: The experience of verb-congruent sentence meaning.

With 10 occurrences of each verb type, this scenario makes a total frequency of 60 tokens of verb-congruent sentence meaning. The user interprets these tokens of verb congruent meaning as instances of the generic VFC, which is entrenched in the user's grammar to a degree that depends on the general frequency of experienced verb-congruent sentence meaning.

In the internal structure of constructions, a subpart link is posited when one construction is a subpart of another construction and exists independently. For instance, the intransitive motion construction is related to the caused-motion construction by a subpart link. Instance links are posited when a particular construction is a special case - a more fully specified version - of the other construction (Goldberg 1995: 80). These definitions of instance links and subpart links imply that every construction $C_{x}$ that is an instance of another construction $C_{y}$ and thus is dominated by $\mathrm{C}_{\mathrm{y}}$ via an instance link $\left(\mathrm{L}_{\mathrm{I}}\right)$, simultaneously dominates $\mathrm{C}_{\mathrm{y}}$ by a subpart link $\left(\mathrm{L}_{\mathrm{S}}\right)$. For instance, the 'drive-crazy' construction is an instance of the resultative construction, which in turn is a schematic subpart (in the internal structure) of the 'drive-crazy' construction. This entails that concrete instances of a particular schematic construction and knowledge of the constructional schema itself mutually motivate each other (see Goldberg 1995: 78-81). This makes sense in the proposed framework, insofar as the productive rule of verb framing is learned from the experience of instances of verb-congruent constructions. At the same 
time, concrete instances of verb-congruent constructions are more likely to be produced and learned where there is robust knowledge of a productive rule of verb framing. In technical terms, high entrenchment (= routinized knowledge) of the generic VFC motivates the user to use concrete VFCs as instantiations of the generic VFC and vice versa (see Figure 2).

Generic VFC: [VERB $\mathrm{ARG}_{0} \ldots \mathrm{ARG}_{\mathrm{n}}$ ] / 'verb congruent meaning'

$$
\mathrm{L}_{\mathrm{I}} \downarrow \uparrow \mathrm{Ls}
$$

Specific VFC: [EAT $\left.\mathrm{ARG}_{0} \ldots \mathrm{ARG}_{\mathrm{n}}\right]$ / 'EATING FRAME $\{$ eater, food $\}$

Figure 2: Motivation of the Verb Frame Construction.

That is to say that the verb-framing rule is relatively more dominant when many instances of verb-congruent meaning are experienced, while verb framing in the encoding of argument structure is motivated given the existence of a strongly entrenched verb-framing rule in the grammar.

At some point, children begin to generalize across item-based constructions and learn constructional form-meaning pairings that are not tied to particular verb lexemes (Diessel 2013: 357). They learn what we understand as argument structure constructions (ASC) in the Golbergian framework (Goldberg 1995), for instance, the ditransitive ASC: [SUBJ V OBJ $\mathrm{OBJ}_{2}$ ] / 'X causes Y to receive Z' (see the previous Section 3). The verb-independency of the learned constructional patterns increases the variability, enabling the verb to occur in different constructions. Compared to the verb-congruent construction scenario with fixed combinations (Figure 1), Figure 3 illustrates a flexible learner scenario with the experience of not only one expected verb-construction combination, but also additional combinations $\left(\mathrm{V}_{\mathrm{n}}-\mathrm{C}_{1-6}\right){ }^{7}$

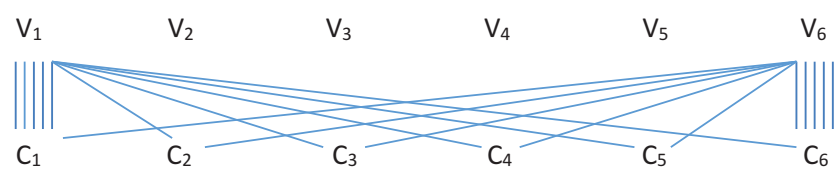

Figure 3: Flexible combining of verbs and constructions.

7 For reasons of simplicity, only the combinations of $V_{1}$ and $V_{6}$ are illustrated in Figure 3. 
With the same token frequency (10) of each of the six verb types, in this imagined scenario only half of the occurrences $(=5)$ match the expected verbcongruent construction $\left(\mathrm{V}_{\mathrm{n}}-\mathrm{C}_{\mathrm{n}}\right)$. The rest are instances of less typical constructions with which the verb may combine. This scenario implies a total frequency of only 30 tokens $(6 \times 5)$ of the verb-congruent construction $\left(V_{n}-C_{n}\right)$, decreasing the number of what the user interprets as instances of the generic VFC by $50 \%$ (cf. the scenario in Figure 1). Thus, it decreases the dominance of the generic VFC in the grammar because the experience of verb-congruent combinations becomes relatively less frequent. From a construction perspective, while the role of verb-independent constructional patterns (ASCs) becomes more central, the verb-framing rule (the generic VFC), and the role of verb framing, become less central in the encoding of argument structure.

While the generic VFC is a usage-based constructionist formalization of the verb-framing rule, the ASC is a constructionist generalization about patterns of frequent usage: a constructional form is paired with schematic conceptual content, for instance, the ditransitive [SUBJ V OBJ $\mathrm{OBJ}_{2}$ / / ' $\mathrm{X}$ causes $\mathrm{Y}$ to receive $\mathrm{Z}$ '. According to Goldberg, the acquisition of the ASC is motivated by its potential role as a predictor of the overall clause meaning. In particular, it is due to the effects of its high category validity, i.e., its relatively high availability (see Goldberg 2006: 117-120). Learned ASCs increase the ability of the child to use syntactic patterns productively. There is abundant evidence that as children get older, and become adults, they extend the use of verbs from one ASC to another - sometimes in unexpected verb-construction combinations (Diessel 2013: 357; see also Tomasello 2000 for a review). As pointed out by Diessel, the verb lexeme continues to have an important role in the encoding of constructions of argument structure in adult language (Diessel 2013: 355). However, with a constructional productive and creative meaning construction in adult language, the experience of a tight verbconstruction relation becomes relatively less dominant. Technically, the generic VFC (the early learned verb-framing rule) and learned instances of verb-congruent sentence meaning remain entrenched in the grammar, though presumably at a relatively lower level, ceteris paribus.

\subsection{Verb-based versus ASC-based constructions and variable type framing}

The strength of the generic VFC in users' grammar in terms of level of entrenchment determines the relative dominance of verb framing in the encoding of argument structure. Being usage-based, it may vary in the adult grammar of different languages. If, in language X, the generic VFC is strongly entrenched in 
the grammar, the role of verb framing dominates the encoding. This makes the encoding of argument structure verb-based in the sense that the meaning skeleton of the intended clause meaning is verb-framed. ${ }^{8}$ Accordingly, we may hypothesize that since Spanish users strongly experience verb-congruent clause meaning (see Sections 1 and 3.1), the generic VFC is strongly entrenched in Spanish grammar. Consequently, the role of verb framing is dominant in the encoding of Spanish argument structure, making it verb-based (the meaning skeleton is verb-framed). This being the case, abstract constructional patterns (ASCs) do not encode the meaning skeleton. From a constructionist point of view, however, it seems unlikely that Spanish users fail to generalize about frequent usage forming constructional ASCs (cf. Goldberg 2006: 120; Pedersen 2013, Pedersen 2014, Pedersen 2016; see Section 1). Thus, I hypothesize that the role of the Spanish ASC is different from that of the English ASC. The dominant Spanish verb frame coerces the constructional ASC into the reduced role of construing the verb-framed meaning skeleton in a specific way. I refer to this role of the Spanish ASC as argument structure construal, because it involves a specifying construal of the meaning skeleton (e.g., degree of specificity construal, or transitive versus intransitive construal). In sum, in the internal structure of the Spanish construction of argument structure, while the verb organizes the meaning skeleton, the ASC specifically provides construal.

Conversely, if, in language $\mathrm{Y}$, the entrenchment of the generic VFC has become relatively weaker, and, correspondingly, the role of verb framing less central, the verb-independent constructional patterns (ASCs) may dominate the verbal predication in the encoding of argument structure. This makes the encoding $A S C(=$ schema $)$-based, and not verb-based. In this case, the role of the ASC is to provide a productive constructional meaning skeleton which is elaborated by the verbal predication. ${ }^{9}$ Due to the relatively lower level of entrenchment in the grammar of the generic VFC (the verb-framing rule), verb framing becomes less dominant in the grammar. It is coerced by the constructional ASC into a different, less central, role. The verb framing elaborates and specifies the skeletal information and, hence requires verb frame-ASC compatibility. Thus, while the generic

8 The term verb-based constructions should not be confused with what Croft (2003) refers to as verb-specific constructions in the grammar of English. The latter is used to account for the relation between the verb meaning and the semantics of the construction when the verb is used in particular constructions.

9 ASC-based encoding involves a productive ASC-skeleton, but it also implies a specific construal. In verb-based encoding, since the specific role of the ASC is to construe a verb-framed meaning skeleton, the role of the ASC accommodates to the dominant role of the verb. In the latter case, the ASC is not a productive meaning skeleton; see Section 2. 
VFC (verb-framing rule) constrains the productivity of the ASC-based construction, a weaker verb constraint on the construction applies as compared to the verbbased encoding (cf. the semantic coherence principle, Goldberg 1995).

Hypothesis: In their internal structure, Spanish and English constructions of argument structure are verb-based and ASC-based respectively.

Example (13) is an instance of Spanish verb-based encoding of intransitive directed motion:

(13) Pedro fue

$$
\text { a-l baño (corr-iendo). }
$$

Pedro move somewhere-PST.3SG to-the bathroom (run-GERUND) 'Pedro ran to the bathroom.'
A) [VERB $\left.\mathbf{A R G}_{0} \ldots \mathbf{A R G}_{\mathbf{n}}\right]$ /
Generic VFC (relatively strong) 'verb-congruent meaning'
B) [SUBJ IR] / 'mover directed motion'
VFC-skeleton
C) [SUBJ VERB OBL (ADJ)] /
ASC-construal 'X moves Y (+ manner)'

The construction instantiates the strong generic VFC (verb-framing rule) that applies in Spanish grammar (A). Thus, verb framing is supposed to dominate the encoding of the intended meaning of directed motion. Accordingly, the verbal predication provides a specific meaning skeleton instantiating the strong generic VFC (B). The dominant verb framing coerces the encoded schematic ASC into the role of providing a specific construal (C). Optionally, this construal may include a specifying manner construal. Figure 4 illustrates the analysis.

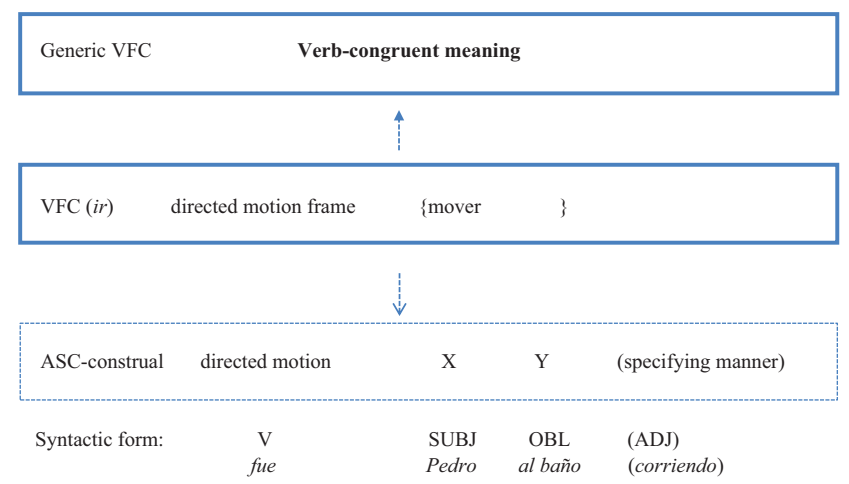

Figure 4: Spanish verb-based encoding. 
The English version in example (14) is a comparable ASC-based construction:

(14) Peter ran to the bathroom
A) [VERB $\left.\mathrm{ARG}_{0} \ldots \mathrm{ARG}_{\mathrm{n}}\right] /$
Generic VFC (relatively weak)
'verb-congruent meaning'
B) [SUBJ RUN] / 'runner runs'
Elaborating VFC
C) [SUBJ VERB OBL] / ASC-skeleton ' $\mathrm{X}$ moves $\mathrm{Y}$ '

The English construction instantiates a strongly entrenched ASC of intransitive motion (C) that overrules the role of verb framing due to the relatively weaker generic VFC (verb-framing rule) (A). Thus, the ASC-skeleton dominates the encoding of directed motion (C). The verbal predication instantiates the verb-framing rule providing a specific verb frame (VFC). However, it is coerced by the dominant ASC into an elaborating role (B). The VFC is a constraint on the productivity of the ASC-skeleton in the sense that the ASC-skeleton has to be compatible with the verb frame. Figure 5 illustrates the ASC-based encoding of (14).

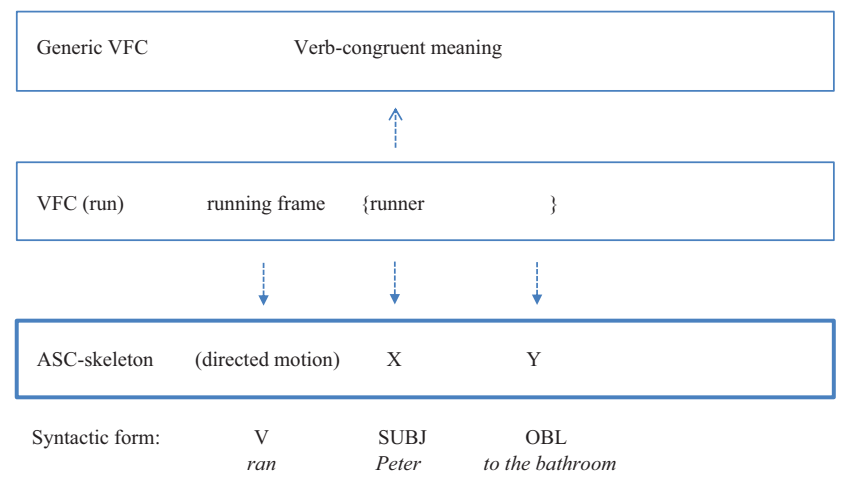

Figure 5: English ASC-based encoding.

The analysis accounts for the initial example (2), repeated here as (15) and (16). While the English version in (16) works perfectly well, (15) is an instance of defective Spanish encoding of directed motion:
^Pedro bail-ó
a la playa.
Pedro dance-PST.3SG to the beach
'Pedro danced to the beach.' 


$\begin{array}{ll}\text { [VERB ARG }_{\mathbf{0}} \ldots \text { ARG }_{\mathbf{n}} \text { ] / 'verb-congruent meaning' } & \text { Strong generic VFC } \\ \text { [SUBJ BAILAR] / 'dancer dances' } & \text { ??VFC-skeleton } \\ \text { [SUBJ VERB OBJ] / 'X moves Y' } & \text { ??ASC-construal }\end{array}$

(16) Peter danced to the beach

[VERB $\mathrm{ARG}_{0} \ldots \mathrm{ARG}_{\mathrm{n}}$ ] / 'verb-congruent meaning' Weaker generic VFC [SUBJ DANCE] / 'dancer dances'

[SUBJ VERB OBL] / ' $\mathrm{X}$ moves $\mathrm{Y}$ '

Elaborating VFC

ASC-skeleton

In the Spanish construction in (15), a strong generic VFC (verb-framing rule) applies, making the encoding verb-based. That is, a dominant meaning skeleton of the intended meaning of directed motion is supposed to be verb-framed. However, the verbal predication based on bailar 'to dance' cannot provide such a verb-framed meaning of directed motion ('to move somewhere'). In addition, the encoded ASC is not a specifying construal of the verb frame provided by bailar 'to dance'. Conversely, in the English version in (16), the strongly entrenched ASC provides a skeleton of the intended meaning of directed motion and dominates the encoding (ASC-based). It overrules the verbframing rule, which is reduced to a compatibility constraint, and the role of the specific verb frame is reduced to 'elaboration': that is, the ASC-skeleton ('X moves $\mathrm{Y}$ ') has to be compatible with the elaborating verb frame ('dancer dances'). This usage is unusual in that we do not usually dance when we move somewhere; but it complies with the compatibility constraint (it is not an impossible way of moving when we move somewhere).

A simple intuition applies: the basic framing may not necessarily provide a complete meaning skeleton of the intended meaning. The completeness of the basic framing may vary, irrespective of the encoding strategy that applies for the language in question. I refer to this variation as variable type framing (Pedersen 2014). However, in terms of communicative transparency and efficiency, the optimal condition seems to be that the meaning skeleton is encoded entirely by means of the expected basic framing device, which depends on the strength of the verb-framing rule. The basic framing device may be a VFC (verb-based language) or an ASC (ASC-based language) as exemplified by 'mover directs motion toward a goal' and 'X moves Y', respectively, in (13) and (14):

The basic framing (VFC- or ASC-skeleton) should preferably provide a complete meaning skeleton (optimal condition)

Basic framing that fulfills the optimal condition will be referred to as complete type framing. As exemplified in the next section, sometimes only a reduced 
meaning skeleton is provided by means of the basic framing. For instance, 'moving down' may frame a more complex 'moving down somewhere' - meaning in a verb-based language; or 'a simple transitive meaning' may frame a more complex 'goal-oriented' meaning' in an ASC-based language. In these cases, the meaning skeleton has to be completed by means of elaboration. Thus, as a minimum condition:

The basic framing (VFC- or ASC-skeleton) elaborated by means of ASCconstrual or verb framing, respectively, should provide a complete meaning skeleton (minimum condition)

Minimally fulfilled framing conditions will be referred to as partial type framing. Unfulfilled framing conditions, as exemplified in (15), will be referred to as defective type framing. In the next section, I briefly exemplify and analyze the variability of the Spanish verb-based TDM construction. In Section 6, I discuss comparable English ASC-based examples.

\subsection{The Spanish TDM construction: Verb framing, transitive construal, and variability}

In the internal structure of the Spanish TDM construction, while the verb organizes the meaning skeleton, the ASC encoding level provides a specific transitive construal and, optionally, a manner construal. Example (17) is a case of verbbased complete type framing of the TDM construction with transitive ASC-construal. The strong generic VFC (=verb-framing rule) dominates the encoding, making it verb-based (A). The transitive verb frame (B) coerces the isomorphic transitive ASC into the role of an argument structure construal that underpins the verb frame (C). Optionally the ASC-construal also involves an adjunct that specifies manner-construal:

(17) Fernando cruz-ó la calle (corr-iendo). Fernando cross-PST.3SG the road (run-GERUND) 'Fernando crossed the road (running).'

A) [VERB ARG . ...ARG $_{\text {n }}$ ] / 'verb-congruent meaning' Generic VFC

B) [SUBJ CRUZAR OBJ] / 'mover moving across location' VFC-skeleton

C) [SUBJ VERB OBJ] / ' $\mathrm{X}$ traverses space $\mathrm{Y}$ ' ASC-construal [------ ADJ] / 'manner-specification' (optional) 
Figure 6 illustrates the analysis.

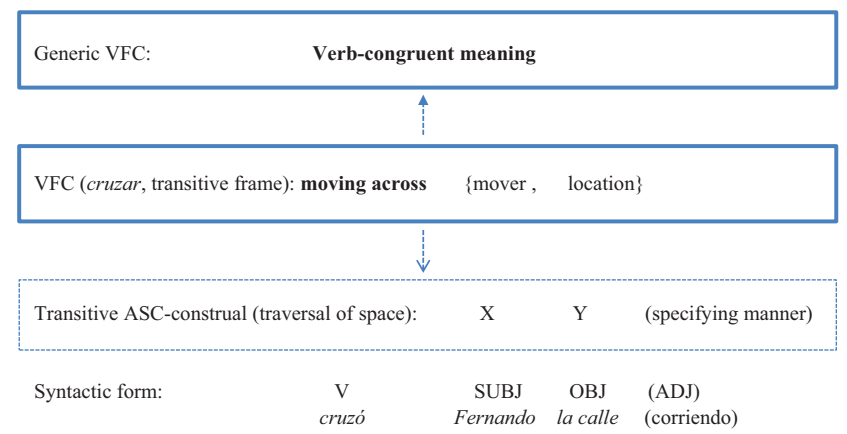

Figure 6: Verb-based TDM construction and isomorphic transitive ASC-construal.

Example (3), repeated as (18), is a case of verb-based partial type framing:

(18) Pedro baj-ó la escalera (corr-iendo). Pedro move down-PST.3SG the stairs (run-GERUND) 'Pedro ran down the stairs.'
A) [VERB ARG ....ARG $_{n}$ ] / 'verb-congruent meaning'
Generic VFC
B) [SUBJ BAJAR] / 'mover moving down in space' VFC-skeleton
C) [SUBJ VERB OBJ] / ' $\mathrm{X}$ traverses space Y' ASC-construal [----- ADJ] / 'manner specification' (optional)

The verb-framing construction instantiates the dominant verb-framing rule (A) providing an incomplete meaning skeleton: 'mover moving down in space' (B). The verb framing coerces the transitive ASC into an elaborating role of transitive construal: ' $\mathrm{X}$ traverses space $\mathrm{Y}$ ' $(\mathrm{C})$, which fulfills the minimum framing condition. This construal alternates with intransitive construal: Pedro baja por la escalera ' $\mathrm{X}$ moves down via $\mathrm{Y}$ '. Figure 7 is a schematic representation of this analysis.

According to the minimum framing condition, the prediction for verb-based encoding will be that when the verb lexeme cannot even partially provide a meaning skeleton of the TDM meaning (see [19]) as expected by the dominant verb framing rule (A), the verb framing is defective (B). It follows directly that the ASC-construal does not turn out to be an elaborating construal coerced by a verbframed meaning skeleton (since the verb framing fails), either as an isomorphic ASC to underpin complete verb framing (cf. [17]), or as an ASC that fulfills the minimum framing condition of partial framing (cf. [18]). As a result, the TDM construction is not licensed by that verb and fails, as exemplified in (19) (cf. [15]): 


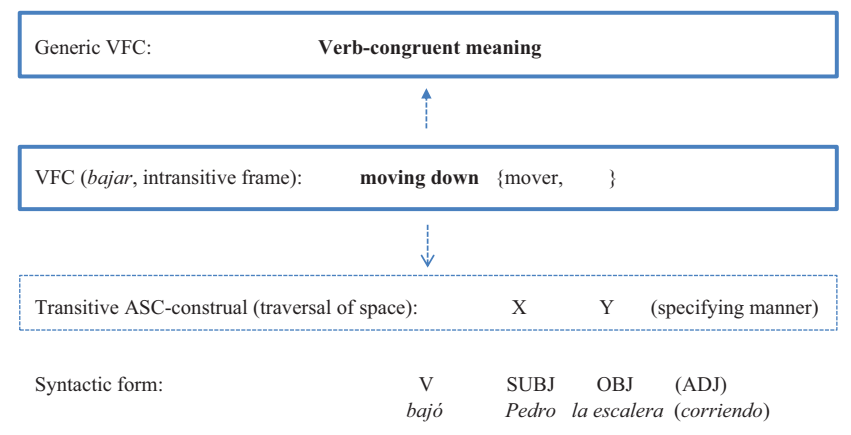

Figure 7: Partial verb framing with transitive ASC-construal.

*Pedro bail-ó el camino.
Pedro dance-PST.3SG the way
'Pedro danced the way/path.'

A) [VERB ARG $_{0} \ldots A_{0} A_{n}$ ] / 'verb-congruent meaning' Generic VFC

B) [SUBJ BAILAR] / 'dancer dancing' ??VFC-skeleton

C) [SUBJ VERB OBJ] / 'X traverses space Y'

??ASC-construal

In the next sections, I present the results from a corpus study in which I examined the validity of the proposed framework for the analysis of the TDM construction. The principal research questions were: (1) Which verb types can be associated with the TDM construction? (2) Are there strong semantic requirements for the verbs that occur in the TDM construction? (3) To what extent does the verb meaning match the core meaning of the TDM construction? and (4) What is the role of verbal transitivity and constructional transitivity in the TDM construction?

\section{Methodology}

I decided to conduct a large-scale corpus study of the Spanish TDM construction to explore the role of verb framing and the transitive ASC by means of quantitative evidence. ${ }^{10}$ The study combined verb lexeme analysis with corpus analysis to map verb meaning with a measure of verb-TDM association in the corpus. I expected to find patterns of \pm alignment between the verb meaning and the

10 Only usage of the TDM construction with reference to motion in physical space was included. Figurative uses of the TDM construction were excluded. 
TDM-construction. This evidence would enable me to analyze - on a quantitative basis - whether the hypothesis of Spanish verb-based encoding and argument structure construal was supported by data from the TDM construction.

I conducted the corpus analysis of verb-TDM association as a standard approach to collexeme analysis (Stefanowitsch and Gries 2003). Collexeme analysis uses the $p$-value of statistical association in distributional corpus analysis as an advanced frequency measure for 'verb in construction'-rankings. It arguably outperforms more simple frequency measures based on raw frequency or relative frequency. One of the main advantages of the method is that it takes into account various parameters of frequency in one single measure of association, the $p$-value, which can be used for the ranking of the verbs. Each parameter affects the specific verb-construction association:

- The frequency of the verb in the TDM construction. The higher the frequency, the higher the measured association and the ranking.

- The general frequency of the verb (in all constructions). If it is relatively high, we expect to observe a higher frequency in the TDM construction, and the association rank is downgraded, accordingly.

- The frequency of other verbs in the TDM construction. The higher the frequency, the higher the competition and the specific verb-association with the construction is relatively lower. The ranking is downgraded, accordingly.

- The general frequency of the other verbs. If they are relatively frequent in other constructions, their association with the TDM construction is lower, and the specific association of the verb with the TDM construction is relatively higher. The verb rank is upgraded, accordingly.

For a technical discussion of the statistical method, see Gries (2012, 2015).

I decided to carry out corpus searches for each of the verbs that potentially might occur in the TDM construction to obtain the raw data for manually sorting out observed instances of the TDM construction. Alternatively, I could have generated raw data by using a general search string to capture all occurrences of the transitive pattern. The latter is the usual procedure used in performing collexeme analysis. Various considerations motivated the chosen procedure. First, it was important not only to include motion verbs that actually occur in the TDM construction but also those motion verbs that are only attestable in other constructions in order to get the most indicative patterns of verb constraints on the TDM construction. In other words, since I wanted to quantify patterns of the verb-construction attraction in terms of probability of occurrence and association strength in the corpus, I was also interested in the type of motion verbs that did not occur very frequently or did not occur at all in the 
TDM construction. Second, taking previous research into account, it was reasonable to focus exclusively on verbs whose lexical semantics fitted into a broad domain of motion. Martínez Vázquez (2001), among others, found that Spanish verbs that did not imply motion of any kind could not be attested in expressions of directed motion. Third, as we might expect, the corpus used does not annotate for the specific semantics of the target construction, which, in addition, has an extremely common form - the general transitive pattern [SUBJ V OBJ]. Therefore, operationally, a general search string to capture the transitive pattern would probably not be the best strategy for extracting potential instances of the target construction for the manual sorting task. Given the size of the corpus (approx. 20 mill.), it would be an almost impossible task, and it would require a disproportionate effort to exclude all types of irrelevant data manually from an extremely large amount of extracted raw data. It would probably also imply a lower reliability in the data selection. In addition, for the reasons already mentioned, it would still be necessary to generate a list of potentially relevant verbs. Such a list, ranked by the association measure of each verb, would enable me to compare the semantics of those verbs that are to some degree actually associated with the TDM construction with the semantics of those that are not, in order to assess the verbal constraints and the role of the construction.

Operationally, the main tasks were (1) to identify verbs that might potentially occur in the TDM construction and (2) to count their frequency in that constructional environment in the corpus. I regarded corpus occurrences of the following observational unit as instances of the TDM construction:

[SUBJ V OBJ] / 'directed motion'

I first generated a frequency list of all verbs in the corpus (around 10,000). From this list, I created a very gross inventory of verbs that might potentially occur in the TDM construction (314). ${ }^{11}$ The data were extracted by using the following search string for each one of the 314 verb searches:

[Verb-lemma] el/la/los/las/un/una/unos/unas [NN*] OR

[Verb-lemma] a la/los/las/un/una/unos/unas [NN] OR [verb-lemma] al $\left[\mathrm{NN}^{\star}\right]^{12}$

11 See the full inventory of verbs in the Appendix.

12 This latter search string identifies the relatively rare cases in which the object is an animate entity marked by the differential object marker a: pasaron a la multitud 'they passed the multitude'. 
Subsequently, I went through the extracted raw data manually to exclude all occurrences that were not instances of the target construction.

The data were extracted from searches in Corpus del Español (Davies 2002), which is a large monolingual corpus available on the Internet. The corpus consists of around 100 million words in approx. 14,000 Spanish/LatinAmerican texts from the 12th to the twentieth centuries. The list of sources is available on the web page. Texts from the 19th and twentieth century were tagged and lemmatized by Mark Davies and Douglas Biber using a tagger developed by the latter - a hybrid probabilistic/rule-based tagger (personal communication with Mark Davies). The present study examines only modern Iberian/Latin-American Spanish in texts and speech from the twentieth century (approx. 20.4 million words). The corpus contains oral as well as written language (interviews and transcripts, newspaper and magazine texts, fiction and academic texts). ${ }^{13}$

In the analysis of the role of verb framing in the encoding of the TDM construction (Section 5), I categorized intransitive (low transitivity) motion verbs according to basic semantic components of the verb lexeme (Path/Manner; lexical aspect ( \pm temporal extension) and directed displacement) and determined the statistical association of each verb with the TDM construction in the corpus. ${ }^{14}$ The determination of the lexical components ' \pm temporal extension', 'directed displacement' (the DD-component), and high vs low transitivity was based on established linguistic procedures and on data from previous research. To avoid a risk of circularity in the argument, the use of intransitive and transitive verbs in the TDM construction was analyzed separately. As diagnostics of verbal transitivity, I used the availability of a simple passive shifted variant '\$[ser 'to be' lemma] [verb-PART]' (e.g., el río fue cruzado 'the river was crossed') in a very large corpus of modern Spanish (CORPESXXI). Since the use of the passive shifted variant for some transitive verbs may be extremely infrequent, it was necessary to carry out these searches in a very large corpus. ${ }^{15}$ See Section 5 for more details.

The statistical analysis was based on Fischer's Exact Test (FET). ${ }^{16}$ FET provides a highly accurate and appropriate measure of statistical association in collexeme analysis (e.g., Gries et al. 2005; Wiechmann 2008). The ranking of

13 Literature: 25\%; academic texts: $25 \%$; newspapers and magazines: $25 \%$, oral: $25 \%$. It should be taken into account that the first three text categories may also include different kinds of oral usage. 14 The semantic analyses by no means claim to be exhaustive and detailed semantic analyses of each verb lexeme.

15 CORPES XXI is from the Real Academia Española (http://www.rae.es/recursos/banco-dedatos/corpes-xxi) and contains approximately 225 million words.

16 Calculations of $p$-values were conducted by using a web-based FET-calculator: http://www. langsrud.com/fisher.htm. 
the verbs in terms of statistical association with the TDM construction was divided into four ranking groups ${ }^{17}$ :

Ranking group 1: Top 20; $p \sim 0$

Ranking group 2: Rank $>20 ; 0<p<0.01$ (significant association)

Ranking group 3: $0.01<p<1$ (no significant association)

Ranking group 4: $p \sim 1$ (not observable in the TDM construction)

I hypothesized that patterns of verb semantics were correlated with patterns of statistical association between the verbs and the TDM-construction in the corpus.

\section{Data and analysis}

Some motion verbs have an inherent transitive meaning. This verb type almost exclusively combines with a second spatial argument with direct object status. I decided to exclude this verb type from the analysis of the general verbal constraints on the TDM construction because an analysis that included this particular verb type would possibly have elements of circularity. Including this frequent verb type with transitive meaning, would make it more difficult to analyze the general role of Spanish verb meaning in the use of the (transitive) TDM construction independently of verb transitivity. The passive shift determines verbs with relatively high transitivity (see Section 2.1). I used the availability of passive shifted variants of two-argument constructions in CORPES XXI (see Section 4) as a diagnostic test to determine relatively high versus low (no) transitivity of the verb ( $\mathrm{H}$ and $\mathrm{L}$, respectively, in the appendix), and hence which verbs should be excluded from the analysis of general verb constraints on the TDM construction. Cf. (20)-(21) and (23)-(24).

The case marker substitution test (by means of a pronominal object marker) identified direct object status in the TDM construction. ${ }^{18}$ The object status observed in the TDM construction cannot always be attributed to the verbal transitivity (high or low [no]) and its role in the construction, which as mentioned above was diagnosed by means of the passive shift; cf. (20) - (22) with (23) - (25):

17 The appendix provides a complete list of the verb ranking. The verbs that do not occur in the TDM construction are statistically ranked according to their general frequency: the higher the frequency the lower the rank (and the higher the ranking number).

18 As shown in Section 2.2, Japanese has a similar directed motion construction in which the locative argument expressing the Ground component is marked with $-o$, the accusative (Muehleisen and Imai 1997). For a discussion of the transitivity of this construction, see also Dubinsky (1985). 
(20) Pedro cruz-ó la calle. (relatively high transitivity of the verb) Pedro cross-PST.3SG the street

'Pedro crossed the street.'

(21) La calle fue cruzada por Pedro. (acceptable passive shift) The street cross-PASS by Pedro

'The street was crossed by Peter.'

(22) Pedro la cruz-ó. (case marked direct object) Pedro ACC cross-PST.3SG

'Pedro crossed it.'

(23) Pedro bajó las

Pedro move down-PST.3SG the escaleras.

(relatively low transitivity of the verb) stairs

'Peter went down the stairs.'

(24) ${ }^{\star}$ Las escaleras fueron bajadas por Pedro. (passive shift not acceptable) The stairs move down-PASS by Pedro 'The stairs were gone down by Pedro.'

(25) Pedro las baj-ó. (case marked direct object) Pedro ACC move down-PST.3SG 'Pedro went down them.'

As the next step, I categorized the Path and Manner verbs identified as having relatively low (no) transitivity, such as bajar 'to move down' (cf. [23]), in terms of fundamental temporal and spatial properties. It is broadly recognized in the linguistic literature that temporal structure (aspect) is central in the lexical meaning of the verb (e.g., Vendler 1967; Dowty 1979; Tenny 1995; among many others). Manner of motion verbs are inherently unspecified for temporal boundedness, and do not usually encode a terminal state (Tenny 1995: 51-54). They denote temporal extension in the sense that they describe a gradual event with duration. Temporal adverbial prepositional phrases of the type in five minutes and for five minutes have been used by Dowty (1979) and others - also applied to Spanish, see, e.g., Hernández Paricio (2004) - as diagnostics for temporal boundedness: María bailó (durante) media hora/?en media hora 'María danced for half an hour/?in half an hour'. 
Temporal extension (= duration) of the motion event is usually associated with spatial extension (cf. Tenny 1995: 65). Several scholars have noted that Manner of motion verbs can be grouped into two different classes: some of the verbs imply displacement (e.g., correr 'to run' or volar 'to fly') while others do not (e.g., bailar 'to dance') (e.g., Morimoto 2001; Martínez Vázquez 2001; see also Allen et al. 2007; Kopecka 2009). Correspondingly, the temporal extension of the motion event may or may not be combined with spatial directedness. That is, the manner of motion may imply \pm directedness (cf. Aske 1989; Pedersen 2014, 2016; Fábregas 2007; Son 2007). For instance, we do not associate the dancing activity with directedness. However, we do associate, for instance, running or walking activities with directedness - not with a specific direction, or path, but with 'moving in some direction'. According to Fábregas (2007), the directional Manner verb type lexicalizes the Path component. ${ }^{19}$ As a slightly different point of view, I have suggested in previous work that this Manner verb type lexicalizes directedness, i.e., 'moving in some direction', but not a specific path (Pedersen 2014, 2016). Cf. the path meaning of Spanish Path verbs (ir 'to move away from speaker x', venir 'to move toward x', entrar 'to enter', bajar 'to move down' ...).

Recent corpus studies have shown that only Spanish Manner of motion verbs that lexicalize directedness allow goal-oriented expressions with the preposition $a$ (Fábregas 2007; Pedersen 2014, 2016; Martínez Vázquez 2001). ${ }^{20}$ The Spanish preposition $a$ is a locative marker, roughly equivalent with the English at, that per se only identifies the end-point in this construction type, not the path (Fábregas 2007; Son 2007). ${ }^{21}$ Following this previous extensive corpus research, we may say that Spanish motion verbs only combine with the locative $a$ in goaloriented constructions if they have directedness as a lexical component. I will refer to this lexical component as directed displacement (DD).

We can now use the combinability with the $a$-marker in the goal-oriented intransitive construction as a diagnostic indicator of the DD-component, taking into account that the verb may still have the DD-component even if the verb is not attestable in the corpus in combination with the $a$ marker. In the present

19 See also Mateu (2008: 246).

20 Some scholars (cited in Beavers et al. 2010) note that this usage in V-framed languages involves only a limited number of Manner of motion verbs (Alonge 1997; Folli and Ramchand 2005; Zubizarreta and Oh 2007; Folli 2008; Gehrke 2008). However, recent large corpus research on Spanish suggests that it is more widespread and involves a larger range of verbs (Pedersen 2016).

21 A number of scholars have suggested that similar prepositions in verb-framed languages like Spanish, French, Italian and Japanese are inherently locative (e.g., Cummins 1998; Dini and Di Tomaso 1995; Fábregas 2007; Jones 1996; Son 2007). 
study, I identified the DD-component in the verb lexeme by means of three indicators of different prioritized strength:

- Indicator (1) Attested combinability with the $a$-marker in the intransitive construction [SUBJ $\mathbf{V}$ a NP]/'telic motion event'. The data is from a previous corpus study of intransitive directed motion, based on the same corpus and the same inventory of motion verbs (see Pedersen 2016). In the appendix, the symbol ' +++ ' assigns this DD-indicator to the verb.

- Indicator (2) The verb has not been observed in the corpus in combination with the $a$-marker in the intransitive construction, but it is what is usually considered a Path verb (and not a Manner verb), indicating that it also has the DD-component. In the appendix, the symbol ' ++ ' assigns this DD-indicator to the verb.

- Indicator (3) The verb is neither a Path verb, nor is it attested in the intransitive construction with the locative $a$, but its meaning is similar to other Manner of motion verbs attested in combination with the $a$-marker (e.g., descorrer 'to run back' or sobrevolar 'overfly'); cf. indicator (1). In the appendix, the symbol ' +' assigns this DD-indicator to the verb.

The lexical meaning of the Spanish Path verb is basically a specific elaboration of directedness by the encoding of a specific path. In addition to the typical bounded reading, some Path verbs also have a durative unbounded reading with temporal extension, e.g., bajar 'to move down', subir 'to move up' (cf. Manner of motion verbs): subió en diez minutos/durante una hora '(he) moved up in an hour/for an hour' (Hernández Paricio 2004: 69).

Another subgroup of Spanish Path verbs, the most common type, encodes boundedness - a crossed boundary to a terminal state. That is, they are not durative, they do not have temporal extension (e.g., entrar 'to enter', salir 'to exit', ir 'to move away', venir 'to come here'): Fernando entró en dos minutos/? durante dos minutos 'Fernando entered in two minutes/?for two minutes'. Note that expressions like Pedro fue una semana a Paris 'Pedro went to Paris for a week' refer to the duration of the stay in Paris, not to the duration of the verbal process of fue (from ir 'to move somewhere'), which is not durative.

In brief, each of the intransitive motion verbs was assigned three lexical components:

1. Manner or Path;

2. \pm directed displacement (DD);

3. \pm temporal extension

For the next step, the verbs were ranked in terms of statistical association with the observed occurrences of the TDM construction in the corpus. They were 
divided into the four ranking groups (see Section 4), and the basic lexical semantics, in terms of the three lexical components, were then linked to the TDM association data.

The most important result of the study was that the use of the TDM construction was strictly constrained by the verb lexeme, suggesting that basically the TDM construction is verb-framed. In the successful TDM construction, verbs with low (no) transitivity indispensably had the lexical components 'directed displacement' (DD) and 'temporal extension'. Intransitive verbs with only one of these components, for instance, frequent Path verbs of the type entrar 'to enter' (with no temporal extension), or type-frequent Manner verbs such as remar/ chapotear 'to paddle' (with no DD-component), were systematically excluded. See appendix.

Frequent intransitive Path verbs with temporal extension, e.g., subir 'to move up', are strongly represented in the top 20 (ranks 7, 10, 14, 19). They are typical cases of partial type framing in the hypothesized framework (see Section 3):
María sub-ió
la calle (corr-iendo).
María move up-PST.3SG the street (run-GERUND)
'María ran up the street.'

The intransitive verb provides a skeleton of the directed motion event ('mover moves up'). The coerced transitive space construal ('X traverses space Y') specifies and completes this meaning skeleton. Likewise, intransitive Manner of motion verbs with the DD-component are among the frequent (top 20) cases of partial type framing. Saltar 'to jump', for instance, is highly associated with the TDM construction (ranked 16):
(27) Paco salt-ó
la valla.
Paco jump-PST.3SG the fence
'Paco jumped over the fence.'

The verb provides a skeleton of the directed motion event in terms of 'directed displacement' and 'temporal extension' ('jumper jumps in some direction'). As in cases with Path verbs, cf. example (26), the coerced transitive space construal ('X traverses space Y') specifies and completes the meaning skeleton. In general, intransitive Manner verbs with the DD-component were broadly represented in the corpus data of the TDM construction. A few of them were top-ranked, but most were not. Many of them were significantly associated with the TDM construction in ranking group 2 (desandar 'to walk back' (21), vadear 'to wade' (23), trepar 'to climb' [25]); or they showed sporadic, rare 
TDM usage in ranking group 3 (correr 'to run' (53), pasear 'to walk for pleasure' (54), andar 'to walk' [59]).

Among the intransitive verbs that were not attested in the TDM construction, I found that Manner verbs with no DD-component (e.g., trastabillar 'to stumble' ranked 147, remar 'to paddle' ranked 178, or bailar 'to dance' ranked 289) were systematically excluded from usage in the TDM construction. The attested type frequency of this verb type in the corpus is very high (132) and the verb type is highly diverse (see Table 2 below and appendix):
*Fernando trastabill-ó las escaleras.
Fernando stumble-PST.3SG the stairs
'Fernando stumbled up/down the stairs.'

Only two verbs of this type, hollar 'to tread, trample' (55) and serpentear 'to slither' (56), were sporadically found in TDM usage. Both verbs were attested in this usage with only one token, and they were both in the lowest TDM ranking group $3(0.01<p<1)$, indicating that the association of these two verbs with the TDM construction was not significant:
Empez-ó a caminar, holl-ando
el centro de la plaza. Start-PST.3SG to walk trample-GERUND the center of the square 'He started to walk, trampling the center of the square.'
(Davies 2002)

Arguably, these two verbs have certain similarities with verbs like vadear 'to wade', trepar 'to climb', or caminar 'to walk'. The latter verbs show clear indications of the DD-component and they were all attested significantly in the TDM construction (see appendix). Thus, in this perspective, the (highly rare) TDM usage of the former two verbs would be verbally motivated as well.

In addition to this type-frequent and diverse category of Manner verbs, highfrequency intransitive Path verbs, such as ir 'to go' (ranked 315), venir 'to come' (ranked 311), or entrar 'to enter' (ranked 310), were also systematically absent in the TDM data:
(30) ^Pedro entr-ó
la casa.
Pedro enter-PST.3SG the house
'Pedro entered the house.'

The verbs in this group have no extension component and represent another verb type that seems to be incompatible with the TDM construction. They were the 
lowest-ranked verbs in terms of statistical association with the TDM construction since, in addition to their absence in the TDM construction, most of them were extremely frequent in other constructions (intransitive constructions of directed motion). Cf. the dominant role of Path verbs in V-framed languages in Talmy's typological framework (see the discussion in Section 6). As we observed for the group of TDM-absent Manner verbs, the attested type frequency of this verb type in the corpus is also high (74) (see Table 2, ranking group 4). Only one verb of this type, montar (b) 'to get onto', has been attested in the TDM construction. However, this usage is highly infrequent, and the verb has the second lowest rank (65) in the third TDM ranking group $(0.01<p<1)$, which indicates that the observed association of this verb with the TDM construction is not significant.

In brief, I found that motion verbs attested with low (no) transitivity only occurred in the TDM construction if they had the DD component combined with a component of temporal extension. Conversely, intransitive motion verbs with no such combined 'DD-extension' component could not be observed in the TDM construction. I interpret this result as evidence of a verb-framed meaning skeleton that, in the TDM construction, coerces the transitive ASC into transitive space construal.

We may expect that transitive verb framing of the TDM construction (by means of verbs attested with relatively high transitivity, ignored in the analysis of verb-TDM association patterns in the first place) is the most frequent type. In the case of cruzar 'to cross', for instance, we understand the denoted transitive crossing-event as a spatial projection of cruzar, as 'crossing something', a spatial region in relation to which the directed motion event takes place: Fernando cruzó la calle 'Fernando crossed the road'. Other examples of transitive Path verbs are atravesar 'to cross ... ', recorrer 'to traverse ... ', rodear 'to go around ... ', or bordear 'to go along the edge of ... '. Transitive verb framing also applies to a little group of Manner of motion verbs with directed displacement (DD), for instance, sobrevolar ('to fly over ... '). In short, the transitive verb framing in the spatial domain is a verbally projected directed spatial extension that involves a second argument of the ground.

In sum, I categorized the motion verbs in terms of three lexical parameters: (1) Manner versus Path, (2) \pm extension and (3) \pm directed displacement (DD). Four lexical profiles were verb types with lexicalized low (no) transitivity and \pm temporal extension. Two lexical profiles were verb types with lexicalized high transitivity and projected spatial extension:

Profile A: Manner - temporal extension

(bailar 'to dance')

María bail-a toda la noche.

María dance-PRS.3SG all the night

'María is dancing all night.' 
Profile B: Manner - DD - temporal extension (correr 'to run')

Fernando corr-e hacia la playa.

Fernando run-PRS.3SG toward the beach

'Fernando is running toward the beach.'

Profile C: Path - DD - temporal extension

(bajar 'to move down')

Pedro baj-a por la escalera.

Pedro move down-PRS.3SG via the stairs

'Pedro is going down the stairs.'

Profile D: Path - DD

(entrar 'to enter')

Lucía entr-a en la casa.

Lucía enter-PRS.3SG in the house

'Lucía enters the house.'

Profile E: Path - DD - transitive spatial extension $\quad$ (cruzar 'to cross')

Juan cruz-a la calle.

Juan cross-PRS.3SG the street

'Juan is crossing the street.'

Profile F: Manner - DD - transitive spatial extension (sobrevolar 'to overfly') Los Americanos sobrevuel-an el territorio iraquí. The Americans overfly-PRS.3SG the territory Iraqi 'The Americans overfly the Iraqi territory.'

The appendix provides the complete results of the corpus analysis of verb-TDM association. The first column shows the rank of the verb in terms of statistical association with the TDM construction. The rank reflects the calculated relative $p$-value in the last column. The closer the $p$-value is to zero, the statistically stronger the lexeme-construction association. From rank 67, the verb was not observed in the TDM construction and the verb rank merely reflects a statistical calculation based on the negative evidence. The higher the general frequency of the verb in other constructions, the stronger is the evidence (in terms of probability) that the verb should not be associated with the TDM construction. In the third column, the evidence of the verbal 'directed displacement' (DD)component is indicated (see this Section). Columns Four and Five show the strength of verbal transitivity (high (H) or low [L]). Columns Six and Seven set 
out the lexical profile of the verb. The eighth column provides the general frequency of the verb in all constructions, and the ninth column shows the observed frequency of the verb in the TDM construction.

The top 20 ranking (see appendix) identified the verbs that showed the statistically highest association with the TDM construction in the corpus. As expected, verbs with a transitive profile (projecting a spatial extension: E-type or F-type) were dominant. Most of the top-ranked verbs were Path verbs, which is in accordance with Talmy's classical typological characterization of Spanish as a verb-framed language (e.g., Talmy 1985, Talmy 2000). Interestingly, however, several Manner of motion verbs were attested with a top rank as well (e.g., sobrevolar 'to overfly' or saltar 'to jump'). I will discuss the potential implication of this result for typological theorizing in Section 6.

Based on the top 20 ranking, we may describe the meaning of the prototypical TDM construction as follows:

TDM construction: $(\mathrm{X})$ directed motion in an extended space $(\mathrm{Y})$

In (31), the verb lexicalizes the path of motion, including the DD-component, and combines with two salient participant roles: the moving figure and the projected spatial region. The transitive ASC-construal is isomorphic with respect to the verb-framed transitive skeleton and adds a specifying construal of manner (en bicicleta 'on bicycle') - see Section 3:

\section{(31) Atravesamos la zona en bicicleta. cross-PST.1PLURAL the zone on bicycle \\ 'We crossed the region on bicycle.'}

The results, including all verb types (high/low (no) transitivity), are summarized in Table 1.22

As shown in Table 2, all the verb types with the lexical profile 'DD-extension' (Verb types B, C, E, F) are represented in the top 20 and the second ranking group $(p<0.01 \rightarrow$ significant association). This is a strong indication that the TDM construction is not only constrained by verb semantics; a specific lexical profile of the verb ('DD-extension') seems to facilitate the verb framing of the TDM construction (by means of complete or partial verb framing).

22 This result does not imply that if the verb lexeme has the combined 'DD-extension' component, it will necessarily be attestable in the TDM construction. Usage patterns are determined by various factors. In fact, some of the verbs that were not attested in the TDM construction (ranked 67-315) have the 'DD-extension' component. 
Table 1: Lexical profile of the verb in the TDM construction.

\begin{tabular}{|c|c|c|c|}
\hline \multirow{2}{*}{$\begin{array}{l}\text { Lexical profile } \\
\text { of the verb }\end{array}$} & High transitivity & \multicolumn{2}{|c|}{ Low transitivity } \\
\hline & \multicolumn{2}{|c|}{ License TDM } & Do not license TDM \\
\hline Profile A & & & Manner - extension \\
\hline Profile B & & $\begin{array}{l}\text { Manner - DD - } \\
\text { temporal extension }\end{array}$ & \\
\hline Profile C & & $\begin{array}{l}\text { Path - DD - } \\
\text { temporal extension }\end{array}$ & \\
\hline Profile D & & & Path - DD \\
\hline Profile E & $\begin{array}{l}\text { Path - DD - spatial } \\
\text { extension }\end{array}$ & & \\
\hline Profile F & $\begin{array}{l}\text { Manner - DD - } \\
\text { spatial extension }\end{array}$ & & \\
\hline
\end{tabular}

Table 2: Verb-TDM association data linked to the verb type frequency.

\begin{tabular}{|c|c|c|c|}
\hline & Lexical profile of the verb & Verb type frequency & Percentage (\%) \\
\hline \multirow{2}{*}{ Ranking group 1} & A) Manner - extension & - & - \\
\hline & B) Manner - DD - temporal extension & 2 & 10 \\
\hline \multirow[t]{2}{*}{ Top 20} & C) Path - DD - temporal extension & 4 & 20 \\
\hline & D) Path - DD & - & - \\
\hline \multirow[t]{2}{*}{$p \sim 0$} & E) Path - DD - spatial extension & 11 & 55 \\
\hline & F) Manner - DD - spatial extension & 3 & 15 \\
\hline --.--.--- & Total: & 20 & 100 \\
\hline \multirow[t]{2}{*}{ Ranking group 2} & A) Manner - extension & - & - \\
\hline & B) Manner - DD - temporal extension & 12 & 36,4 \\
\hline \multirow[t]{2}{*}{$21-53$} & C) Path - DD - temporal extension & 6 & 18,2 \\
\hline & D) Path - DD & - & - \\
\hline \multirow[t]{2}{*}{$0<p<0.01$} & E) Path - DD - spatial extension & 12 & 36,4 \\
\hline & F) Manner - DD - spatial extension & 3 & 9,0 \\
\hline --.----- & Total: & 33 & 100 \\
\hline \multirow[t]{2}{*}{ Ranking group 3} & A) Manner - extension & 2 & 15,4 \\
\hline & B) Manner - DD - temporal extension & 9 & 69,2 \\
\hline \multirow[t]{2}{*}{$54-66$} & C) Path - DD - temporal extension & - & - \\
\hline & D) Path - DD & 1 & 7,7 \\
\hline \multirow[t]{2}{*}{$0.01<p<1$} & E) Path - DD - spatial extension & 1 & 7,7 \\
\hline & F) Manner - DD - spatial extension & - & - \\
\hline -.-.-.-.-. & Total: & 13 & 100 \\
\hline
\end{tabular}


Table 2: (continued)

\begin{tabular}{llrr}
\hline & Lexical profile of the verb & Verb type frequency & Percentage (\%) \\
\hline Ranking group 4 & A) Manner - extension & 132 & 53,0 \\
\cline { 2 - 3 } & B) Manner - DD - temporal extension & 25 & 10,1 \\
\multirow{5}{*}{$p \sim 315$} & C) Path - DD - temporal extension & 16 & 6,4 \\
& D) Path - DD & 73 & 29,3 \\
& E) Path - DD - spatial extension & 3 & 1,2 \\
& F) Manner - DD - spatial extension & - & - \\
& Total: & 249 & 100 \\
\hline
\end{tabular}

The transitive verbs (E- and F-types) were represented by $70 \%$ of the top 20 verbs (e.g., cruzar 'to cross'), 45\% of the second ranking group (e.g., transitar 'to pass across') and by a single verb in the third ranking group (entrecruzar 'to cross'). Thus, transitive verb types - mostly Path verbs - were, as expected, strongly represented in the TDM construction. The intransitive Manner and Path verbs (B- and C-types) were represented by $30 \%$ of the top 20 verbs (e.g., subir 'to move up', saltar 'to jump'), 55\% of the second ranking group (e.g., trepar 'to climb', ascender 'to move up') and approx. $70 \%$ of the third ranking group (only Manner verbs, e.g., andar 'to walk'). Broadly speaking, the Path verbs showed higher ranks compared to the Manner verbs.

The broad distribution of high transitivity verbs and low transitivity verbs in the ranking groups with significant association with the TDM construction suggests that the Spanish verb framing of the TDM construction may be complete verb framing (transitive verb types) as well as partial verb framing (intransitive verb types). Accordingly, I interpret the role of the transitive ASC as a coerced transitive construal of the verb-framed - complete or partial - meaning skeleton of the TDM-construction.

\section{Discussion - a contrastive perspective}

In this section, I discuss how and why the English usage of the TDM construction in some aspects diverges from the Spanish usage. In particular, I argue that the distinction between verb-based and schema(ASC)-based constructions can explain the crosslinguistic differences and intra-linguistic variation. In the final part, I discuss how the proposed analysis is related to the typological distinction between V-framed and S-framed languages, and I show that it is more suitable than the latter to account for the typological differences and the variation (cf. Talmy 1991, Talmy 2000). 
The present study has shown that a combination of the directed displacement (DD) component and the extension component in the verb lexeme is mandatory and the major framing constraint on the Spanish TDM construction (see Section 5). While the use of common intransitive Path verbs like bajar 'to move down' (C-type) is allowed in this construction (Pedro bajó la escalera 'Pedro went down the stairs'), the verb-framing constraint systematically excludes very common Spanish Path verbs like entrar 'to enter' (D-type) ( ${ }^{\star}$ Pedro entró la casa 'Pedro entered the house'). I argued that this usage constraint is due to the absent extension component in the verb. In contrast, parallel English Path verbs are typical in the TDM construction (e.g., enter, exit, approach, leave, escape, flee). In addition, the observed Spanish verb-framing constraint excludes Spanish parallels to the extended use of English Manner of motion verbs in the TDM construction (e.g., swim, dive, sail, navigate, row, paddle, ski, roam, swarm, wander, parade ...). I argued that this usage constraint is due to the absence of the DD-component in this type of Spanish Manner verbs (A-type). See Section 5 and Appendix.

In general, the English TDM construction seems to be less verb constrained compared to the Spanish construction, which is an expected difference (cf. Section 1). Givón explained the transitive construction of directed motion as a deviation from prototypical transitivity (cf. Hopper and Thompson 1980) by constructing a locative entity as a patient object: Peter entered the house (Givón 1984: 96-99, Givón 1993). According to Givón, goal or source locatives, constructed as direct objects, become patient-like, appearing to be affected by the event. The locative argument accedes to objecthood whenever it undergoes a change of state. Givón provides a long list of examples to argue for the meaning of affectedness, confrontation or conquest in the TDM variants. For instance, she approached the house (> she moved toward the house); they entered the house ( $>$ they went into the house); she swam the channel (> she swam across the channel); she escaped him (> she escaped from him); they deserted her (> they moved away from her); she left him (> she moved away from him) (Givón 2001: 131). In escaping someone, one overcomes their resistance; one does not merely move away from them. Deserting a person may leave this person distraught and helpless, while merely moving away may not. The notion of confrontation may be involved in approaching the house and the notion of 'conquest' in swimming the channel to account for the transitive motion event (see also Gropen et al. 1991). Givón's analysis is focused on there being a general transitive constraint on the construction. It is not clear, however, in what sense the locative argument in Peter entered/left the house undergoes a change of state, becoming patientlike, or involves affectedness, confrontation or conquest, even in a figurative sense. Examples like (32) seem to be even more problematic: 


\section{(32) Peter turned the corner}

The principal meaning of turning the corner is 'directed motion' - unless it is a metaphorical idiom as in (33), in which some kind of 'conquest' is involved:

(33) After nine months of poor sales we've finally turned the corner (Dictionary.cambridge.org)

On the one hand, the application of the condition of objecthood, as suggested by Givón, is not always convincing; on the other hand, English does not seem to have a general verb constraint on the TDM construction, such as the verb-framing constraint we have observed for Spanish. In (34), I analyze the English version of the TDM construction with the verb enter in the suggested framework, according to which the English construction is schema(ASC)-based (cf. Figure 8):

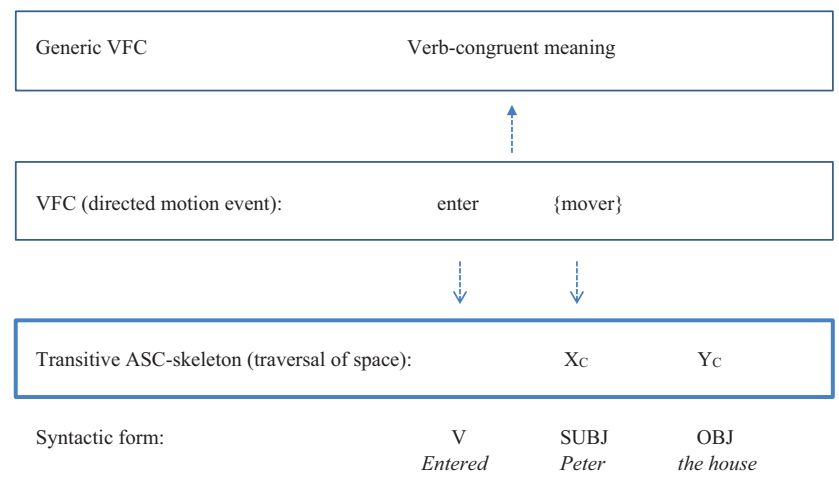

Figure 8: ASC-based partial framing of the TDM construction.

(34) Peter entered the house

$\left[\right.$ VERB $\left.\mathrm{ARG}_{0} \ldots \mathrm{ARG}_{\mathrm{n}}\right] /$

Generic VFC (relatively weak)

'verb-congruent meaning'

[SUBJ ENTRAR] / 'Mover moved inside'

Elaborating VFC

[SUBJ V OBJ] / ' $X$ traverses space $Y$ '

Partial framing (ASC-skeleton) 
The (relatively weak) verb-framing rule is overruled by the transitive ASC, which is a generalized constructional pattern of the TDM construction. However, the implication of the minimum framing condition is that, when the ASC encoding of the skeletal meaning is only partial, it has to be completed lexically (see Section 3.2). In (34), the transitive ASC is used as a skeleton of the motion event, 'X traverses space Y', which only partially represents the intended goal-oriented meaning: ' $X$ moves into Y'. In other words, example (34) is not only about traversal of space, but about goal-oriented motion in space. The lexical profile of the verb enter - which is 'goal-oriented motion' - fulfils this incomplete constructional skeleton. Consequently, the contribution of the verb lexeme is not a specification of manner of motion (which is characteristic in Germanic languages); the verb provides a necessary completion of the meaning skeleton. This analysis also applies, e.g., to other Path verbs such as leave, pass, cross:

\section{(35) Peter passed the school}

(36) Peter left the house

It follows from this analysis that partial framing of the TDM construction and the minimum condition tend to exclude the characteristic Germanic manner of motion specification by the verb as defective, when the intended meaning is 'goal-oriented':

(37) ${ }^{\star}$ Peter walked/drove/crawled/stumbled... the school/house/work/town...

Due to the manner of motion verb meaning, the intended goal-oriented meaning cannot be achieved by means of the transitive TDM-skeleton and lexical elaboration. Alternatively, the goal-oriented meaning may be achieved by a goal-marker (instead of the verbal encoding) as instances of complete (ASC-based) intransitive framing of the goal-oriented meaning, enabling the characteristic manner specification (example adapted from Tenny 1995: 61):

(38) Peter walked/drove/crawled/stumbled home

[SUBJ V OBL] / 'X moves Y'

Complete ASC-framing

This analysis makes the correct prediction that (39) is not a possible encoding option for a goal-oriented motion event reading of run:

${ }^{\star}$ Peter ran the school/house/center/beach 
Nevertheless, depending on the contextual interpretation and due to the polysemy of the transitive ASC (Goldberg 1995: 31-39 and 116-119), example (39) implies another, more central, transitive, reading: 'he governed the school/ house/center ...' (cf. he ran the business, and the diversity of transitive uses of run). According to this latter reading, $\mathrm{X}$ is actually doing something to $\mathrm{Y}$ (the school/house/center ...), which corresponds to an intended transitive meaning of affectedness. Consequently, this reading reflects that (39) is interpreted as an instance of complete ASC framing of transitive affectedness. Thus, defective partial framing with Manner verbs, such as (37) and (39), may turn into successful transitive framing when the context allows for an interpretation of the transitive ASC-skeleton as complete transitive framing of the intended meaning. The same argument applies when the intended meaning is the typical TDMmeaning ' $\mathrm{X}$ traverses space $\mathrm{Y}$ '. In (40), for instance, the context allows us to interpret the TDM construction as implying this transitive spatial meaning as the intended meaning ${ }^{23}$ :

\section{(40) Peter climbed the tree / ran the marathon}

In this case, the transitive ASC skeleton is also an instance of complete framing of the intended meaning. This was exactly what we saw in some of Givón's examples (e.g., she swam the channel) discussed above. Other examples of Manner verbs that may be used in an intended locative transitive context would be to row, paddle or to dive. In some cases, these TDM constructions may be interpreted as complete framing of some sense of 'affectedness' (e.g. 'Peter "confronted"/“conquered" the tree/the marathon'). In these diverse interpretations of complete transitive framing, the ASC-skeleton is successfully elaborated by a Manner of motion verb. Similar contextual interpretations of the transitive meaning in (37) as a locative spatial traversal (e.g., ??'Peter traversed the space of school'), or as an 'affectedness'-reading (e.g., ??'Peter did something to the school), are hardly possible due to the concrete meaning context that suggests a goal-oriented reading.

It is relevant to discuss how the results of the present study relate to the typological distinction between verb-framed and satellite-framed languages (Talmy 1991, Talmy 2000). In Talmy's framework, V-framed languages, such as Spanish, lexicalize the main event by the verb (conflating Motion and Path), and may express the co-event in an adjunct, typically by adding a gerund or an

23 As the co-editor has pointed out, run has several transitive uses and may also be used with extent objects like run $\boldsymbol{a}$ mile, which are similar to the discussed transitive locative usage (cf. run the marathon). 
adverbial. S-framed languages, such as English, lexicalize the main event in a satellite, and the co-event by the verb (conflating Motion and Manner/Cause). The TDM construction challenges the Talmyan distinction between V-framed and S-framed languages. First of all, there is no satellite involved in the TDM construction in either of the two languages. We may go even further in this characterization: the surface form of the TDM construction is the same in Spanish and English. Moreover, Path verbs as well as Manner verbs are regularly observable as the main verb in both languages (see Section 5, the appendix and the discussion in this Section). Hence, in S-framed languages such as English, it hardly makes sense to assign co-event to the verb meaning (opposed to the main event) as a typological distinction.

The observed unavailability of some types of frequent Spanish Path verbs in the TDM construction is unaccounted for in Talmy's typology, let alone the frequent and (in his framework) unexpected use of parallel Path verbs in English. In English, which is categorized as an S-framed language, we would expect this usage to be unavailable. For instance, the use of the Spanish entrar 'to enter' is often highlighted as exemplary of the conflation of Motion and Path in the typology. Nevertheless, it is excluded from the Spanish TDM construction. Conversely, the mentioned frequent use of the English Path verb to enter in the TDM construction is basically unexplained in the typology proper (e.g., Peter entered the room). This usage does not only include so-called Latinate verbs, which is the usual way to account for this unexpected usage (e.g., Croft et al. 2010; Talmy 2000): Peter entered/left/fled the house. See also the discussion in Beavers et al. (2010: 343-45, 350). In short, the distinct usage constraints on the TDM construction that we have observed in Spanish and English respectively, hardly fit with the Talmyan lexicalization patterns, nor is it attributable to the formal resources (e.g., particles) available in each of the two languages.

Instead, I have argued, we should adopt another distinction: verb-based constructions (e.g., Spanish) versus schema-based constructions (e.g., English). In the internal structure of constructions, this distinction endows constructional (= schematic) meaning of the ASC with a relatively more powerful role in the Talmyan S-languages, such as English. This is so, firstly because the constructional meaning overrides (coerces) verb framing, enabling expressions such as Peter danced to the beach (cf. [2]). Secondly, the context seems to facilitate distinct types of constructional (transitive) framing, which allows different verb types. For instance, cf. Peter entered the house (partial transitive framing of goal-oriented motion event), to Peter paddled the river (complete transitive framing of the locative motion event). Conversely, the constructional meaning of the ASC has a relatively secondary role in V-languages, such as Spanish, because the verb framing overrides the constructional meaning, which is 
coerced into a different role, a specifying argument structure construal. This role of the verb and the ASC in Spanish impedes parallel expressions like ${ }^{\star}$ Pedro bailó a la playa, cf. (2), `Juan entró la casa 'Juan entered the house' or `Pedro remó el río 'Pedro paddled the river', in which the verb framing of the skeletal meaning is defective. The role of the context may also be important in Spanish (V-framed) usage, particularly as a constraint on argument structure construal in partial verb framing, but, above all, the encoding of the intended meaning skeleton is strongly verb constrained (cf. Beavers et al. 2010). A framework based on the verb-based versus schema-based distinction seems to capture the essential crosslinguistic differences and intra-linguistic variability of all types of directed motion constructions.

Comparing V-framed languages, the TDM construction seems to show intratypological differences as well. For instance, according to Muehleisen and Imai (1997), in Japanese, the directed motion constructions involve a specific type of transitive Ground-Path verbs (GP verbs), in addition to what they call directional Path verbs (DP verbs). This kind of evidence, according to which the Ground component arguably has a key role in Japanese, is also a challenge to a typological framework based on the distinction between $\mathrm{V}$-framed and S-framed languages, because the framing of path is essential in the latter framework. The 'verb-based vs schema-based' distinction more flexibly allows for intra-typological variation, for instance regarding the TDM construction (e.g., Spanish vs Japanese).

The proposed framework is applicable to other semantic domains, some of which are included in the most recent versions of the Talmyan typological framework, for instance resultatives of the type change-of-state (Talmy 2000, vol. II: 223):

(41) He blew the candle out

Complete ASC-framing of change-of-state [SUBJ V OBJ OBL] / 'X caused Y to become Y'

According to the proposed framework, in English the change-of-state meaning should preferably be completely encoded at the constructional level by means of an ASC (cf. Goldberg 1995: chap. 1 and 8). Example (41) provides such a complete constructional framing of the change-of-state meaning and a verbal specification of 'cause'. The unsuccessful variant in (42) is a case of partial schematic (ASC) framing of the state change meaning by means of a simple transitive ASC, in which the lexical completion fails:

(42) ??He blew the candle Defective partial ASC-framing of change-of-state [SUBJ V OBJ] / 'X affects Y' 
Since blow is not a change-of-state verb, its verbal completion does not comply with the minimum condition according to which the basic framing (transitive ASC) elaborated by means of verb framing should provide a complete meaning skeleton (see Section 3.2). For comparison, (43) is an instance of successful simple transitive framing, because the intended state change meaning is achieved by means of the verbal elaboration:

(43) He extinguished the fire

Partial ASC-framing of change-of-state

This encoding option implies that the verb cannot have the same role of specifying the causal factor as in (41). In other words, the Talmyan co-event is missing. If (42) were interpreted as complete transitive ASC-framing of affectedness between the blowing agent and the affected candle, with a verbal specification of 'cause', in principle it might be successful. However, it would still tend to be unsuccessful, firstly, because the encoded transitive meaning of affectedness (cf. he blew the car) would probably not be the intended one, and secondly, because the encoded meaning of impact of affectedness on the candle would not lead naturally to an inference of the intended meaning of state change of the candle.

The suggested analysis accounts for the fact that (42) is a hardly acceptable transitive variant in English, but it also provides an explanation of the successful parallel Spanish version in (45), which is a perfectly acceptable alternative to the exemplar Spanish usage in $(44)^{24}$ :

Pedro apag-ó la vela
Pedro put off-PST.3SG the candle
(de un soplido).
with a blow

'Pedro blew out the candle.'

(Talmy 2000, vol II: 223)
(45) Pedro sopl-ó la vela.
Pedro blow-PST.3SG the candle
'Pedro blew out the candle.'

Complete verb framing of change-of-state

Assuming that Spanish encoding is verb-based, the verb lexeme (soplar 'to blow') in (45) cannot provide a complete verb-framed meaning skeleton of

24 This is the Spanish version of (41) provided in the typological literature. The change of state is completely framed by the verb apagar 'to put off' and it is specified by the verb-independent adjunct (de un soplido). This version, however, is probably not as typical as usually assumed, at least in spoken language. 
change-of-state. However, (45) is a successful instance of partial verb framing of a suitable simple transitive construction. The verbal activity of soplar 'to blow' implies 'directedness of moving air toward potentially affected entities' (cf. the verb components of aspectual extension and the DD-component in the TDM construction). Thus, it is a partial verb framing of a transitive transfer of wind from the agent to an affected goal. The verb-framed meaning skeleton coerces the transitive ASC to provide a transitive construal that completes the transitive meaning ('goal affected by wind transfer'). The change-of-state meaning is directly inferable. In addition, the analysis explains straightforwardly why the framing of state change in (46) fails; cf. (41):

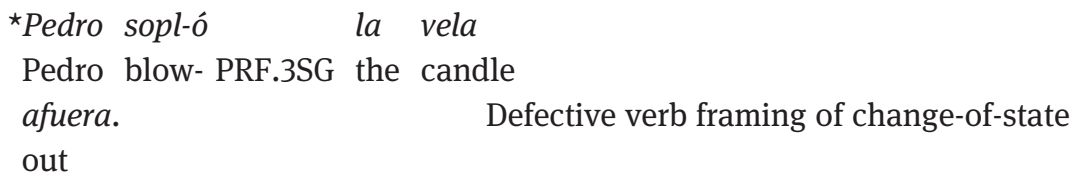

Defective verb framing of change-of-state out

'Pedro blew out the candle.'

A full verb-independent constructional meaning skeleton with a change-of-statemarker (afuera 'out') is not an option in Spanish (verb-based), and the verb soplar 'to blow' cannot provide the change-of-state meaning skeleton by means of complete verb framing. In addition, since there is no generalized constructional (resultative) ASC pattern of this type in Spanish to support and complete the verb framing by means of argument structure construal, it cannot be an instance of partial verb framing of state change either.

To sum up, I have argued that while the distinction between V-framed and S-framed languages and between verb-based and schema (ASC)-based encoding are closely related, the latter is more flexible and better suited to account for the crosslinguistic and intra-linguistic variability of the TDM construction and related constructions.

\section{Conclusion}

In this corpus study, I have examined the role of verb meaning and constructional meaning in the internal structure of the Spanish transitive directed motion (TDM) construction. Based on 'verb-TDM construction' association data, I found that Spanish motion verbs attested with low (no) transitivity only occurred in the TDM construction if they had the 'temporal extension' component combined with the 'DD-component' (directed displacement). Conversely, verbs with no such combined 'extension-DD' component could not be observed in the TDM 
construction. Intransitive verbs with only one of these components, for instance frequent Path verbs of the type entrar 'to enter' (with no temporal extension), or type-frequent Manner verbs of the type remar/chapotear 'to paddle' (with no DDcomponent), were systematically excluded from this usage.

Based on these results, I suggest that the Spanish TDM construction is verbbased in the sense that the meaning skeleton is verb-framed. The constructional meaning of the transitive construction is overridden by the verb frame, accommodated and coerced into the specifying role of what I have termed argument structure construal.

As expected, the transitive verbs (the E-type, in particular) were the most strongly represented in the TDM construction. However, the broad distribution of high transitivity verbs as well as low (no) transitivity verbs in all the ranking groups with significant association with the TDM construction, suggests that the Spanish verb framing of the TDM construction may be complete verb framing (high transitivity verb types) as well as partial verb framing (low/no transitivity verb types). Accordingly, in the internal structure of the TDM construction I interpret the role of the transitive construction as an isomorphic or completing argument structure construal of the verb-framed meaning skeleton.

I have discussed how and why the seemingly parallel English TDM construction in some aspects diverges from the Spanish TDM construction. The study shows that a well-defined profile of the verb lexeme is mandatory and the major constraint on the Spanish TDM construction. This verb constraint systematically excludes the use of Spanish parallels to a number of typical English Path verbs in the TDM construction (e.g., enter, exit, go, approach, leave, escape, flee ...) as well as the productive English TDM usage of typefrequent Manner verbs (e.g., to paddle the river). While the appropriate context may further condition the successful verb framing (particularly in cases of partial verb framing), the Spanish encoding of the intended meaning skeleton is, above all, strongly verb constrained. The crucial issue seems to be the different role of verb meaning and constructional meaning in the framing of the TDM construction in the two languages, and with respect to English, in particular, the important role of the context to facilitate the interpretation of the proper constructional (transitive) skeleton of the intended meaning (cf. Beavers et al. 2010). I interpret this evidence as an indication that, in the internal structure of the English TDM construction, the encoding is schema (ASC)based. In contrast to Spanish verb-based constructions, the role of the transitive ASC is to provide a constructional skeleton, which is elaborated by the verbal predication. By using this distinction of basic framing type, and the principles of variable type framing (complete vs partial framing), I have shown how we could 
understand the variability of the TDM construction differently in the two languages.

Compared to the typological distinction between V-framed and S-framed languages in the Talmyan framework (e.g., Talmy 2000), the distinction between verb-based and schema (ASC)-based encoding seems to be better suited to account for the crosslinguistic differences. This is so particularly because this framework is broad enough to capture constructions of directed motion in general, including the TDM construction and the intra-linguistic variation, let alone constructions of argument structure in other semantic domains.

In a broader perspective, the suggested constructionist framework accounts, firstly, for the ungrammaticality in Spanish of so-called "complex predicate" constructions in which the verb meaning is incongruent with the intended sentence meaning as exemplified initially by the intransitive directed-motion construction in (2). Secondly, the framework accounts for the usage of transitive constructions of directed motion (TDM) that includes types of incongruent coding of the verb and the construction, as initially exemplified in (3). Thirdly, the framework accounts for crosslinguistic and intra-linguistic variation when compared to English. In general terms, this study hypothesizes that Spanish constructions of argument structure are verb-based and that constructional meaning has a different role in Spanish compared to the role it arguably has in English (cf. Goldberg 1995, Goldberg 2006). The role of the Spanish argument structure construction, I hypothesize, is to add argument structure construal to the meaning skeleton provided by the verb. The distinction between verb-based and ASCbased encoding, combined with the principles of variable type framing for each encoding type, is a broadly conceptualized framework, which is context sensitive and, potentially, may capture inter- and intra-linguistic variability in a broad array of semantic domains.

Acknowledgements: I am grateful to two anonymous reviewers and to the coeditor/board of Linguistics for valuable comments on earlier versions of this article. 


\section{Appendix: Complete list of verb rankings}

\begin{tabular}{|c|c|c|c|c|c|c|c|c|c|}
\hline \multirow[t]{2}{*}{ RANK } & \multirow[t]{2}{*}{ VERBS } & \multirow[t]{2}{*}{ DD } & \multicolumn{2}{|c|}{ TRANSITIVITY } & \multirow{2}{*}{$\begin{array}{l}\text { LEXICAL } \\
\text { PROFILE }\end{array}$} & \multirow[t]{2}{*}{ TYPE } & \multirow{2}{*}{$\begin{array}{r}\text { ALL } \\
\text { USES }\end{array}$} & \multirow[t]{2}{*}{ TDM } & \multirow[t]{2}{*}{ FET $(p)$} \\
\hline & & & High & Low & & & & & \\
\hline 1 & cruzar 'to cross ...' & +++ & $\mathrm{H}$ & & $\begin{array}{l}\text { PATH-DD- } \\
\text { SPA EXT }\end{array}$ & $\mathrm{E}$ & 1984 & 669 & 0 \\
\hline 2 & atravesar 'to cross ...' & ++ & $\mathrm{H}$ & & $\begin{array}{l}\text { PATH-DD- } \\
\text { SPA EXT }\end{array}$ & $E$ & 1324 & 583 & 0 \\
\hline 3 & invadir 'to invade ... & ++ & $\mathrm{H}$ & & $\begin{array}{l}\text { PATH-DD- } \\
\text { SPA EXT }\end{array}$ & $E$ & 962 & 222 & 0 \\
\hline 4 & recorrer 'to traverse ...' & ++ & $\mathrm{H}$ & & $\begin{array}{l}\text { PATH-DD- } \\
\text { SPA EXT }\end{array}$ & $\mathrm{E}$ & 1694 & 542 & 0 \\
\hline 5 & alcanzar 'to reach ...' & +++ & $\mathrm{H}$ & & $\begin{array}{l}\text { PATH-DD- } \\
\text { SPA EXT }\end{array}$ & $E$ & 5342 & 222 & $6.9 e-253$ \\
\hline 6 & seguir 'to follow ... ' & +++ & $\mathrm{H}$ & & $\begin{array}{l}\text { PATH-DD- } \\
\text { SPA EXT }\end{array}$ & $E$ & 15,308 & 236 & $1.0 \mathrm{e}-170$ \\
\hline 7 & subir 'to move up' & +++ & & $\mathrm{L}$ & $\begin{array}{l}\text { PATH-DD- } \\
\text { TEMP EXT }\end{array}$ & C & 3209 & 133 & $1.9 e-151$ \\
\hline 8 & rodear 'to go around ...' & ++ & $\mathrm{H}$ & & $\begin{array}{l}\text { PATH-DD- } \\
\text { SPA EXT }\end{array}$ & $\mathrm{E}$ & 1858 & 112 & $5.7 e-146$ \\
\hline 9 & pisar 'to walk on, step on' & +++ & $\mathrm{H}$ & & $\begin{array}{l}\text { MAN-DD- } \\
\text { SPA-EXT }\end{array}$ & $\mathrm{F}$ & 526 & 74 & $3.8 \mathrm{e}-125$ \\
\hline 10 & bajar 'to move down' & +++ & & $\mathrm{L}$ & $\begin{array}{l}\text { PATH-DD- } \\
\text { TEMP EXT }\end{array}$ & $\mathrm{C}$ & 2589 & 100 & $4.0 \mathrm{e}-111$ \\
\hline 11 & $\begin{array}{l}\text { bordear 'to move along } \\
\text { the edge of ...' }\end{array}$ & ++ & $\mathrm{H}$ & & $\begin{array}{l}\text { PATH-DD- } \\
\text { SPA EXT }\end{array}$ & $\mathrm{E}$ & 192 & 40 & $8.7 e-76$ \\
\hline 12 & $\begin{array}{l}\text { sobrevolar 'fly over ..., } \\
\text { overfly ... }\end{array}$ & + & $\mathrm{H}$ & & $\begin{array}{l}\text { MAN-DD- } \\
\text { SPA EXT }\end{array}$ & $\mathrm{F}$ & 58 & 31 & $1.4 \mathrm{e}-74$ \\
\hline 13 & abordar 'to bord ...' & ++ & $\mathrm{H}$ & & $\begin{array}{l}\text { PATH-DD- } \\
\text { SPA EXT }\end{array}$ & $E$ & 580 & 49 & $5.0 e-72$ \\
\hline 14 & doblar 'to turn' & ++ & & $\mathrm{L}$ & $\begin{array}{l}\text { PATH-DD- } \\
\text { TEMP EXT }\end{array}$ & $\mathrm{C}$ & 525 & 45 & $1.4 \mathrm{e}-66$ \\
\hline 15 & esquivar 'to avoid ...' & ++ & $\mathrm{H}$ & & $\begin{array}{l}\text { PATH-DD- } \\
\text { SPA EXT }\end{array}$ & $\mathrm{E}$ & 129 & 33 & $4.1 \mathrm{e}-66$ \\
\hline 16 & saltar 'to jump' & +++ & & $\mathrm{L}$ & $\begin{array}{l}\text { MAN-DD- } \\
\text { TEMP EXT }\end{array}$ & B & 1233 & 55 & $3.3 e-65$ \\
\hline 17 & perseguir 'to chase ... ' & ++ & $\mathrm{H}$ & & $\begin{array}{l}\text { PATH-DD- } \\
\text { SPA EXT }\end{array}$ & $\mathrm{E}$ & 927 & 44 & $1.1 \mathrm{e}-53$ \\
\hline 18 & rondar 'to wander about' & + & & $\mathrm{L}$ & $\begin{array}{l}\text { MAN-DD- } \\
\text { TEMP EXT }\end{array}$ & B & 188 & 28 & $4.6 e-49$ \\
\hline 19 & remontar 'to move up' & +++ & & $\mathrm{L}$ & $\begin{array}{l}\text { PATH-DD- } \\
\text { TEMP EXT }\end{array}$ & C & 392 & 30 & $2.2 \mathrm{e}-43$ \\
\hline 20 & escalar 'to scale ...' & + & $\mathrm{H}$ & & $\begin{array}{l}\text { MAN-DD- } \\
\text { SPA EXT }\end{array}$ & $\mathrm{F}$ & 71 & 16 & $7.9 e-32$ \\
\hline
\end{tabular}


(continued)

\begin{tabular}{|c|c|c|c|c|c|c|c|c|c|}
\hline \multirow[t]{2}{*}{ RANK } & \multirow[t]{2}{*}{ VERBS } & \multirow[t]{2}{*}{ DD } & \multicolumn{2}{|c|}{ TRANSITIVITY } & \multirow{2}{*}{$\begin{array}{l}\text { LEXICAL } \\
\text { PROFILE }\end{array}$} & \multirow[t]{2}{*}{ TYPE } & \multirow{2}{*}{$\begin{array}{r}\text { ALL } \\
\text { USES }\end{array}$} & \multirow[t]{2}{*}{ TDM } & \multirow[t]{2}{*}{ FET $(p)$} \\
\hline & & & High & Low & & & & & \\
\hline 21 & $\begin{array}{l}\text { desandar 'to walk back } \\
\text { along the same path' }\end{array}$ & + & & $\mathrm{L}$ & $\begin{array}{l}\text { MAN-DD- } \\
\text { TEMP EXT }\end{array}$ & B & 28 & 13 & $5.3 e-31$ \\
\hline 22 & descender 'to move down' & +++ & & $\mathrm{L}$ & $\begin{array}{l}\text { PATH-DD- } \\
\text { TEMP EXT }\end{array}$ & $\mathrm{C}$ & 987 & 28 & $1.5 e-28$ \\
\hline 23 & vadear 'to wade' & + & & $\mathrm{L}$ & $\begin{array}{l}\text { MAN-DD- } \\
\text { TEMP EXT }\end{array}$ & B & 18 & 11 & $3.0 \mathrm{e}-28$ \\
\hline 24 & husmear 'to sniff around' & + & & $\mathrm{L}$ & $\begin{array}{l}\text { MAN-DD- } \\
\text { TEMP EXT }\end{array}$ & B & 42 & 13 & $3.6 e-28$ \\
\hline 25 & trepar 'to climb' & +++ & & $\mathrm{L}$ & $\begin{array}{l}\text { MAN-DD- } \\
\text { TEMP EXT }\end{array}$ & B & 271 & 18 & $1.6 \mathrm{e}-25$ \\
\hline 26 & patrullar 'to patrol' & + & $\mathrm{H}$ & & $\begin{array}{l}\text { MAN-DD- } \\
\text { SPA EXT }\end{array}$ & $\mathrm{F}$ & 20 & 10 & $1.4 \mathrm{e}-24$ \\
\hline 27 & penetrar 'to penetrate ...' & +++ & $\mathrm{H}$ & & $\begin{array}{l}\text { PATH-DD- } \\
\text { SPA EXT }\end{array}$ & $\mathrm{E}$ & 771 & 21 & $1.9 e-21$ \\
\hline 28 & rebasar 'to overflow ... ', & ++ & $\mathrm{H}$ & & $\begin{array}{l}\text { PATH-DD- } \\
\text { SPA EXT }\end{array}$ & $\mathrm{E}$ & 191 & 13 & $5.6 \mathrm{e}-19$ \\
\hline 29 & $\begin{array}{l}\text { circunnavegar 'to } \\
\text { circumnavigate ... }\end{array}$ & ++ & $\mathrm{H}$ & & $\begin{array}{l}\text { MAN-DD- } \\
\text { SPA EXT }\end{array}$ & $\mathrm{F}$ & 11 & 5 & $1.3 e-12$ \\
\hline 30 & circundar 'to surround ...' & ++ & $\mathrm{H}$ & & $\begin{array}{l}\text { PATH-DD- } \\
\text { SPA EXT }\end{array}$ & $\mathrm{E}$ & 68 & 7 & $3.8 \mathrm{e}-12$ \\
\hline 31 & cercar 'to surround ... & ++ & $\mathrm{H}$ & & $\begin{array}{l}\text { PATH-DD- } \\
\text { SPA EXT }\end{array}$ & $\mathrm{E}$ & 129 & 8 & $6.9 e-12$ \\
\hline 32 & $\begin{array}{l}\text { transitar 'to move along a } \\
\text { place' }\end{array}$ & +++ & $\mathrm{H}$ & & $\begin{array}{l}\text { PATH-DD- } \\
\text { SPA EXT }\end{array}$ & $\mathrm{E}$ & 231 & 9 & $2.2 \mathrm{e}-11$ \\
\hline 33 & cabalgar 'to ride a horse' & + & & $\mathrm{L}$ & $\begin{array}{l}\text { MAN-DD- } \\
\text { TEMP EXT }\end{array}$ & B & 101 & 7 & $6.6 e-11$ \\
\hline 34 & $\begin{array}{l}\text { costear 'to move along the } \\
\text { edge/the coast' }\end{array}$ & ++ & & $\mathrm{L}$ & $\begin{array}{l}\text { PATH-DD- } \\
\text { TEMP EXT }\end{array}$ & $\mathrm{C}$ & 51 & 5 & $6.3 e-9$ \\
\hline 35 & torcer 'to turn' & ++ & & $\mathrm{L}$ & $\begin{array}{l}\text { PATH-DD- } \\
\text { TEMP EXT }\end{array}$ & $\mathrm{C}$ & 202 & 7 & $8.4 \mathrm{e}-9$ \\
\hline 36 & caminar 'to walk' & +++ & & $\mathrm{L}$ & $\begin{array}{l}\text { MAN-DD- } \\
\text { TEMP EXT }\end{array}$ & B & 2347 & 16 & $7.0 e-8$ \\
\hline 37 & $\begin{array}{l}\text { contornear 'to go } \\
\text { around ...' }\end{array}$ & ++ & $\mathrm{H}$ & & $\begin{array}{l}\text { PATH-DD- } \\
\text { SPA EXT }\end{array}$ & $\mathrm{E}$ & 8 & 3 & $1.0 \mathrm{e}-7$ \\
\hline 38 & $\begin{array}{l}\text { patear 'to walk/move on } \\
\text { foot around a place' }\end{array}$ & + & & $\mathrm{L}$ & $\begin{array}{l}\text { MAN-DD- } \\
\text { TEMP EXT }\end{array}$ & B & 125 & 5 & $5.8 \mathrm{e}-7$ \\
\hline 39 & $\begin{array}{l}\text { merodear 'to walk around } \\
\text { and prowl' }\end{array}$ & + & & $\mathrm{L}$ & $\begin{array}{l}\text { MAN-DD- } \\
\text { TEMP EXT }\end{array}$ & B & 56 & 4 & $8.0 e-7$ \\
\hline 40 & desbordar 'to overflow ...' & ++ & $\mathrm{H}$ & & $\begin{array}{l}\text { PATH-DD- } \\
\text { SPA EXT }\end{array}$ & $E$ & 285 & 6 & $1.8 \mathrm{e}-6$ \\
\hline 41 & acosar 'to persue' & ++ & $\mathrm{H}$ & & $\begin{array}{l}\text { PATH-DD- } \\
\text { SPA EXT }\end{array}$ & $\mathrm{E}$ & 185 & 4 & $4.0 \mathrm{e}-6$ \\
\hline
\end{tabular}


(continued)

\begin{tabular}{|c|c|c|c|c|c|c|c|c|c|}
\hline \multirow[t]{2}{*}{ RANK } & \multirow[t]{2}{*}{ VERBS } & \multirow[t]{2}{*}{ DD } & \multicolumn{2}{|c|}{ TRANSITIVITY } & \multirow{2}{*}{$\begin{array}{l}\text { LEXICAL } \\
\text { PROFILE }\end{array}$} & \multirow[t]{2}{*}{ TYPE } & \multirow{2}{*}{$\begin{array}{r}\text { ALL } \\
\text { USES }\end{array}$} & \multirow[t]{2}{*}{ TDM } & \multirow[t]{2}{*}{ FET $(p)$} \\
\hline & & & High & Low & & & & & \\
\hline 42 & ascender 'to move up' & +++ & & $\mathrm{L}$ & $\begin{array}{l}\text { PATH-DD- } \\
\text { TEMP EXT }\end{array}$ & C & 760 & 8 & $6.1 \mathrm{e}-6$ \\
\hline 43 & montar (a) 'to ride'a & +++ & & $\mathrm{L}$ & $\begin{array}{l}\text { MAN-DD- } \\
\text { TEMP EXT }\end{array}$ & B & 1353 & 10 & $9.7 e-6$ \\
\hline 44 & $\begin{array}{l}\text { pasar 'to pass, to go } \\
\text { through' }\end{array}$ & +++ & $\mathrm{H}$ & & $\begin{array}{l}\text { PATH-DD- } \\
\text { SPA EXT }\end{array}$ & $E$ & 21,593 & 51 & $1.5 e-5$ \\
\hline 45 & rastrear (a) 'to track ... ${ }^{\text {b }}$ & ++ & $\mathrm{H}$ & & $\begin{array}{l}\text { PATH-DD- } \\
\text { SPA EXT }\end{array}$ & $E$ & 95 & 3 & $2.4 \mathrm{e}-4$ \\
\hline 46 & atropellar 'to run over ...' & + & $\mathrm{H}$ & & $\begin{array}{l}\text { MAN-DD- } \\
\text { SPA EXT }\end{array}$ & $\mathrm{F}$ & 150 & 3 & $8.9 e-4$ \\
\hline 47 & rebosar 'to overflow ... ' & ++ & $\mathrm{H}$ & & $\begin{array}{l}\text { PATH-DD- } \\
\text { SPA EXT }\end{array}$ & $E$ & 42 & 2 & $1.3 e-3$ \\
\hline 48 & virar 'to turn' & +++ & & $\mathrm{L}$ & $\begin{array}{l}\text { PATH-DD- } \\
\text { TEMP EXT }\end{array}$ & $\mathrm{C}$ & 67 & 2 & $3.2 \mathrm{e}-3$ \\
\hline 49 & profundizar 'to get into ...' & ++ & & $\mathrm{L}$ & $\begin{array}{l}\text { PATH-DD- } \\
\text { TEMP EXT }\end{array}$ & $\mathrm{C}$ & 269 & 3 & $4.7 e-3$ \\
\hline 50 & brincar 'to jump' & +++ & & $\mathrm{L}$ & $\begin{array}{l}\text { MAN-DD- } \\
\text { TEMP EXT }\end{array}$ & B & 96 & 2 & $6.4 \mathrm{e}-3$ \\
\hline 51 & $\begin{array}{l}\text { volar 'to move through the } \\
\text { air, to fly' }\end{array}$ & +++ & & $\mathrm{L}$ & $\begin{array}{l}\text { MAN-DD- } \\
\text { TEMP EXT }\end{array}$ & B & 995 & 5 & $8.3 e-3$ \\
\hline 52 & circunvalar 'to go round ...' & ++ & $\mathrm{H}$ & & $\begin{array}{l}\text { PATH-DD- } \\
\text { SPA EXT }\end{array}$ & $\mathrm{E}$ & 8 & 1 & $9.8 \mathrm{e}-3$ \\
\hline 53 & correr 'to run' & +++ & & $\mathrm{L}$ & $\begin{array}{l}\text { MAN-DD- } \\
\text { TEMP EXT }\end{array}$ & B & 3912 & 11 & 0.01047 \\
\hline 54 & $\begin{array}{l}\text { pasear 'to walk for } \\
\text { pleasure' }\end{array}$ & +++ & & $\mathrm{L}$ & $\begin{array}{l}\text { MAN-DD- } \\
\text { TEMP EXT }\end{array}$ & B & 764 & 4 & 0.01542 \\
\hline 55 & hollar 'to tread, trample' & - & & $\mathrm{L}$ & $\begin{array}{l}\text { MAN-TEMP } \\
\text { EXT }\end{array}$ & $A$ & 18 & 1 & 0.02190 \\
\hline 56 & serpentear 'to slither' & - & & $\mathrm{L}$ & $\begin{array}{l}\text { MAN-TEMP } \\
\text { EXT }\end{array}$ & A & 35 & 1 & 0.04215 \\
\hline 57 & $\begin{array}{l}\text { descorrer 'to move/run } \\
\text { back' }\end{array}$ & + & & $\mathrm{L}$ & $\begin{array}{l}\text { MAN-DD- } \\
\text { TEMP EXT }\end{array}$ & B & 35 & 1 & 0.04215 \\
\hline 58 & entrecruzar 'to cross ... ' & ++ & $\mathrm{H}$ & & $\begin{array}{l}\text { PATH-DD- } \\
\text { SPA EXT }\end{array}$ & $\mathrm{E}$ & 46 & 1 & 0.05503 \\
\hline 59 & andar 'to walk' & +++ & & $\mathrm{L}$ & $\begin{array}{l}\text { MAN-DD- } \\
\text { TEMP EXT }\end{array}$ & B & 3330 & 8 & 0.05676 \\
\hline 60 & navegar 'to navigate' & +++ & & $\mathrm{L}$ & $\begin{array}{l}\text { MAN-DD- } \\
\text { TEMP EXT }\end{array}$ & B & 340 & 2 & 0.06636 \\
\hline 61 & errar 'to wander about' & + & & $\mathrm{L}$ & $\begin{array}{l}\text { MAN-DD- } \\
\text { TEMP EXT }\end{array}$ & B & 81 & 1 & 0.09486 \\
\hline 62 & galop(e)ar 'to gallop' & + & & $\mathrm{L}$ & $\begin{array}{l}\text { MAN-DD- } \\
\text { TEMP EXT }\end{array}$ & B & 124 & 1 & 0.14151 \\
\hline
\end{tabular}


(continued)

\begin{tabular}{|c|c|c|c|c|c|c|c|c|c|}
\hline \multirow[t]{2}{*}{ RANK } & \multirow[t]{2}{*}{ VERBS } & \multirow[t]{2}{*}{ DD } & \multicolumn{2}{|c|}{ TRANSITIVITY } & \multirow{2}{*}{$\begin{array}{l}\text { LEXICAL } \\
\text { PROFILE }\end{array}$} & \multirow[t]{2}{*}{ TYPE } & \multirow{2}{*}{$\begin{array}{r}\text { ALL } \\
\text { USES }\end{array}$} & \multirow[t]{2}{*}{ TDM } & \multirow[t]{2}{*}{ FET $(p)$} \\
\hline & & & High & Low & & & & & \\
\hline 63 & $\begin{array}{l}\text { deambular 'to walk } \\
\text { around' }\end{array}$ & + & & $\mathrm{L}$ & $\begin{array}{l}\text { MAN-DD- } \\
\text { TEMP EXT }\end{array}$ & B & 127 & 1 & 0.14467 \\
\hline 64 & resbalar 'to slide' & +++ & & $\mathrm{L}$ & $\begin{array}{l}\text { MAN-DD- } \\
\text { TEMP EXT }\end{array}$ & B & 285 & 1 & 0.29580 \\
\hline 65 & montar (b) 'get onto'c & +++ & & $\mathrm{L}$ & PATH-DD & $\mathrm{D}$ & 1353 & 2 & 0.49559 \\
\hline 66 & viajar 'to travel' & +++ & & $\mathrm{L}$ & $\begin{array}{l}\text { MAN-DD- } \\
\text { TEMP EXT }\end{array}$ & B & 1832 & 1 & 0.89511 \\
\hline * & - & & & & - & - & - & 0 & 1 \\
\hline
\end{tabular}

${ }^{a}$ Montar (a) represents only one of two verb meanings of motion: montar (a) 'to ride' and montar (b) 'get onto'. ' Rastrear (a) represents only one of two verb meanings of motion: rastrear (a) 'to track' and rastrear (b) 'to fly at ground level'. 'Montar (b) 'get onto' represents only one of two verb meanings of motion: montar (a) 'to ride' and montar (b) 'get onto'.

*abajar 'to go down' (= bajar) (67), circuir 'to encircle, surround' (68), refluir 'to flow (back)' (69), desbarrar 'to slip' (70), despeñar(se) 'to fall down from a rock' (71), pisotear 'to step on, tread repeatedly and violently' (72), bandear 'to cross' (73), contonear(se) 'to swagger' (74), desembarcar 'to disembark' (75), jinetear 'to ride a horse' (76), rebullir 'to begin to move' (77), caracolear 'to turn around' (78), vaguear 'to roam/wander' (79), serpear 'to wriggle, creep, slither, meander' (80), tra(n)smigrar 'to migrate, transmigrate' (81), descaminar(se) 'to go the wrong way' (82), expatriar(se) 'to exile' (83), bornear 'to round, bend, twist' (84), callejear 'to walk around the streets' (85), hormiguear 'to swarm' (86), tremolar 'to flutter' (87), sesgar 'to cross to one side' (88), renguear 'to limp' (89), zozobrar 'to be moving in danger of sinking' (90), culebrear 'to zigzag' (91), ambular 'to wander about' (92), bogar 'to row/sail' (93), campanear 'to swing' (94), piafar 'to paw the ground, to stamp' (95), pirar(se) 'to go away (informal)' (96), rastrear (b) 'to fly at ground level' (97), rolar 'to list, heel, veer' (Rastrear (b) 'to fly at ground level' represents only one of two verb meanings of motion: rastrear (a) 'to track' and rastrear (b) 'to fly at ground level'.) (98), apelotonar 'to crowd together' (99), pavonear 'to strut about' (100), afluir 'to flow in/into/to/toward' (101), retemblar 'to shutter, shake' (102), descarrilar 'to derail' (103), acuclillar(se) 'to crouch down, squat' (104), agazapar(se) 'to crouch (105), fondear 'to move at the bottom of the sea' (106), renquear 'to limp' (107), aupar(se) 'to lift up' (108), repatriar(se) 'to repatriate' (109), trepidar 'to shake, vibrate' (110), encamar(se) 'to go to bed' (111), rumbear 'to follow a direction' (112), rezagar(se) 'to fall behind' (113), boxear 'to box' (114), bracear 'to brace/wrestle' (115), colear '(of an animal) to move its tail, to wag' (116), encabritar(se) 'to rear up' (117), taconear 'to tap shoes with heels' (118), traquetear 'to move repeatedly' (119), desperezar(se) 'to stretch' (120), acurrucar(se) 'to curl up' (121), vagabundear 'to wander' (122), levitar 'to levitate' (123), remecer(se) 'to shake, rock, swing' (124), hamacar (se)/hamaquear(se) 'to rock, swing' (125), columpiar(se) 'to swing' (126), pilotar 'to steer/drive/ fly' (127), radiar '(ir)radiate' (128), zigzaguear 'zigzag' (129), ciar 'to go backwards' (130), arbolar 'to rear (horse)/going steep (aircraft)' (131), fugar(se) 'to flee, to run away' (132), cojear 'to limp' (133), escabullir(se) 'to slip away' (134), palmotear 'to applaud' (135), toquetear 'to mess about, finger' (136), encumbrar(se) 'to reach the top' (137), arremolinar(se) 'to crowd around' (138), pedalear 'to pedal' (139), recular 'to back/recoil/walk backwards/back' (140), patinar 'to skate' 
(141), zapatear 'to stamp one's feet' (142), ladear 'to move away, to move on the hillside' (143), orillar 'to skirt, to go around' (144), bambolear(se) 'to swing/falter' (145), cimbr(e)ar(se) 'to sway' (146), trastabillar 'to stumble/stagger' (147), aminorar 'to slow down' (148), cejar 'to back' (149), peregrinar 'travel around, go on a pilgrimage' (150), bailotear 'to dance about' (151), codear 'to move your elbow to move forward' (152), maniobrar 'to manoeuvre' (153), espetar 'to skewer' (154), pulular 'to swarm' (155), regatear 'to dribble' (156), zambullir(se) ‘to go down into water' (157), migrar 'to migrate' (158), rodar 'to roll' (159), chapotear 'to move noisily in water/ mud' (160), divagar 'to wander' (161), rezumar 'to seep/ooze' (162), retozar 'to run about' (163), aligerar 'to hurry up' (164), gatear 'to crawl, to climb like a cat' (165), rotar 'to rotate' (166), campear 'to go to graze' (167), zarandear(se) 'bustle about' (168), bullir 'to boil, to stir' (169), manotear 'to wave one's hands, to gesticulate' (170), bucear 'to dive' (171), revolcar(se) 'to wallow' (172), patalear 'to stamp one's feet' (173), reptar 'to move like a reptile' (174), aletear 'to flap, to flutter to wriggle' (175), ondular 'to wave/undulate' (176), atracar '(of a ship) to reach port' (177), remar 'to row, to paddle' (178), cabecear 'to nod, shake one's head' (179), cerner (se)/cernir(se) 'to swing the hips (walking)' (180), ondear 'to undulate, to sway' (181), esquiar 'to ski' (182), reclinar(se) 'to lean' (183), menear(se) 'to move, to wag' (184), surtir 'to gush/ spurt out' (185), empinar(se) 'to stand up' (186), manar 'flow' (187), blandir(se) 'to swing/ stagger' (188), enroscar(se) 'to coil' (189), trotar 'to trot' (190), fluctuar 'to fluctuate' (191), tambalear 'to stagger' (192), encorvar(se) 'to bend, to curve' (193), cundir 'to spread' (194), apear(se) 'to get off' (195), abalanzar(se) 'to dash to' (196), tripular 'to drive, sail' (197), naufragar '(of a ship, people in a ship) to sink' (198), torear 'to fight bulls' (199), tiritar 'to shiver, to tremble' (200), arquear(se) 'to bend oneself' (201), titubear 'to falter' (202), curvar(se) 'to curve, bend' (203), zarpar '(of a ship) to set off' (204), corretear 'to run about' (205), danzar 'to dance' (206), confluir 'to merge (flows, streams)' (207), atajar 'to take a short cut' (208), chorrear 'to gush out, drip' (209), revolotear 'to fly around, to flutter' (210), distanciar(se) 'to move away from' (211), encaramar(se) 'to move up to the top of' (212), rebotar 'to bounce' (213), enderezar(se) 'to become straight' (214), mecer(se) 'to swing, rock' (215), esparcir(se) 'to move in different directions' (216), desplomar(se) 'to collapse' (217), adentrar(se) 'to go into the interior part of' (218), arrimar(se) 'to move closer to' (219), balancear 'to swing' (220), botar 'to bounce, rebound' (221), aterrizar 'to land' (222), arrodillar(se) 'to kneel down' (223), estrellar (se) 'to crash' (224), agachar(se) 'to crouch' (225), vacilar 'to stagger' (226), vagar 'to wander' (227), desfilar 'to parade, to walk in file' (228), despegar 'to take off' (229), tumbar(se) 'to lie down' (230), largar(se) 'to leave' (231), arribar '(of a ship) to reach port, to arrive' (232), derrumbar(se) 'to fall down' (233), dispersar(se) 'to disperse' (234), refugiar(se) 'to flee' (235), vibrar 'to vibrate' (236), discurrir 'to flow, run' (237), recostar(se) 'to lean or to lie down' (238), embarcar(se) 'to go on board' (239), volcar(se) 'to overturn, learn over' (240), mudar(se) 'to go from one place to another' (241), espantar(se) 'to run away ' (242), voltear 'to turn/roll over' (243), apresurar(se) 'to hurry up' (244), erguir(se) 'to straighten, stand up' (245), sumir 'to sink, plunge' (246), exiliar(se)/exilar(se) 'to exile' (247), estremecer(se) 'to tremble, shiver' (248), nadar 'to swim' (249), precipitar(se) 'to fall down from a high place' (250), aplaudir 'to applaud' (251), tropezar 'to bump into, trip over' (252), emigrar 'to emigrate' (253), sumergir(se) 'to dive, submerge' (254), retroceder 'to go back, to back down' (255), posar(se) 'to land, alight' (256), estirar(se) 'to stretch out' (257), planear '(of a plane, a bird) to glide' (258), desviar(se) 'to divert' (259), retornar 'to return, to go back' (260), chocar 'to crash' (261), deslizar(se) 'to slide' (262), oscillar 'to oscillate, to swing' (263), acelerar 'to speed up, to accelerate' (264), aproximar(se) 'to move closer to' (265), asentar(se) 'to sit down' (266), fluir 'to flow in/into/to/ toward' (267), temblar 'to shiver, to tremble' (268), agitar(se) 'to shake, to move about' (269), 
sacudir(se) 'to shake oneself' (270), acostar(se) 'to lie down' (271), acceder(se) 'to gain access into' (272), adelantar 'to move forwards' (273), arrojar(se) 'to throw oneself' (274), inclinar(se) 'to incline' (275), flotar 'to float or to move smoothly' (276), derivar 'to drift' (277), circular 'go in a circuit' (278), encerrar(se) 'to enclose' (279), hundir(se) 'to collapse, to sink' (280), alzar(se) 'to rise' (281), apartar(se) 'to move away from' (282), huir 'to flee' (283), marchar(se) 'to go, to go away, to march' (284), acudir 'to go to a specific place' (285), manejar 'to drive' (286), girar 'to turn, change direction, to rotate/spin' (287), arrastrar(se) 'to drag oneself' (288), bailar 'to dance' (289), trasladar(se) 'to move from one place to another' (290), tender(se) 'to stretch, to lie down' (291), elevar(se) 'to move upwards' (292), escapar(se) 'to escape' (293), alejar(se) 'to move far away (294), 'retirar(se) 'to retreat' (295), conducir 'to drive' (296), tirar(se) 'to throw oneself' (297), avanzar 'to move forwards' (298), lanzar(se) 'to throw oneself' (299), regresar 'to come back' (300), echar(se) 'to lie down, to move towards' (301), extender(se) 'to stretch' (302), mover(se) 'to move oneself' (303), levantar(se) 'to stand up, to raise' (304), acercar(se) 'to move closer to' (305), dirigir(se) 'to head to' (306), partir 'to leave' (307), caer(se) 'to fall down' (308), sentar(se) 'to sit down' (309), entrar 'to enter' (310), venir 'to come' (311), salir 'to exit' (312), volver 'to come back' (313), llegar 'to arrive' (314), ir 'to go somewhere' (315).

\section{References}

Allen, Shanley, Asli Özyürek, Sotaro Kita, Amanda Brown, Reyhan Furman, Tomoko Ishizuka \& Mihoko Fujii. 2007. Language-specific and universal influence in children's syntactic packaging of manner and path: A comparison of English, Japanese, and Turkish. Cognition 102. $16-48$.

Alonge, Antonietta. 1997. Semantica lessicale e proprietà sintattiche dei verbi di movimiento italiani: Analisi di dati acquisiti da dizionari di macchina e da un corpus testuale computerizzato. In Luciano Agostiniani, Paola Bonucci, Giulio Giannecchini, Franco Lorenzi \& Luisella Reali (eds.), Atti del III convegno della Società Internazionale di Linguistica e Filologia Italiana, 31-63. Naples: Edizioni Scientifiche Italiane.

Aske, Jon 1989. Path predicates in English and Spanish: A closer look. Proceedings from the Berkeley Linguistics Society annual meeting (BLS 15), 1-14. Berkeley, CA: Berkeley Linguistics Society.

Beavers, John, Beth Levin \& Shiao Wei Tham. 2010. The typology of motion expressions revisited. Journal of Linguistics 46(3). 1-58.

Blumenthal-Dramé, Alice. 2012. Entrenchment in usage-based theories: What corpus data do and do not reveal about the mind. Berlin \& Boston: De Gruyter Mouton.

Boas, Hans. 2011. Coercion and leaking argument structures in construction grammar. Linguistics 49(6). 1271-1303.

Boas, Hans. 2013. Cognitive construction grammar. In Graeme Trousdale \& Thomas Hoffmann (eds.), Oxford handbook of construction grammar, 233-252. Oxford: Oxford University Press.

Boas, Hans C. 2003. A Constructional approach to resultatives. Stanford, CA: CSLI Publications.

Boas, Hans C. 2005. Semantic frames as interlingual representations for multilingual lexical databases. International Journal of Lexicography 18(4). 445-478.

Boas, Hans C. 2010. The syntax-Lexicon continuum in construction grammar. A case study of English communication verbs. Belgian Journal of Linguistics 24(1). 54-82. 
Bosque, Ignacio. 2009. Nueva gramática de la lengua española. Real Academia Española (NGLE). Madrid: Real Academia Española (RAE).

Braine, Martin D. S. 1976. Children's first word combinations. Monographs of the Society for Research in Child Development 41(1). 1-104.

Butler, Christopher S. \& Francisco Gonzálvez-Garcîa. 2014. Exploring functional-cognitive space. Amsterdam \& Philadelphia: John Benjamins.

Bybee, Joan. 2007. Frequency of use and the organization of language. Oxford: Oxford University Press.

Campos, Héctor. 1999. Transitividad e intransitividad. In Ignacio Bosque \& Violeta Demonte (eds.), Gramática descriptiva de la lengua española, vol. 2. 1519-1574. Madrid: Espasa.

Cano Aguilar, Rafael. 1981. Estructuras sintácticas transitivas en el español actual. Madrid: Gredos.

Choi-Jonin, Injoo \& Laure Sarda. forthcoming. Transitive motion verbs in French and in Korean. In Hubert Cuyckens, Walter de Mulder \& Tanja Mortelmans (eds.), Variation and change in adpositions of movement (Studies in language companion series). Amsterdam \& Philadelphia: John Benjamins.

Croft, William. 1991. Syntactic categories and grammatical relations: The cognitive organization of information. Chicago, IL: The University of Chicago Press.

Croft, William. 2001. Radical construction grammar. Oxford: Oxford University Press.

Croft, William. 2003. Lexical rules vs. constructions: A false dichotomy. In Hubert Cuyckens, Thomas Berg, René Dirven \& Klaus-Uwe Panther (eds.), Motivation in language: Studies in honor of Günter Radden, 49-68. Amsterdam \& Philadelphia: John Benjamins.

Croft, William, Jóhanna Barðdal, Willem Hollmann, Violeta Sotirova \& Chiaki Taoka. 2010. Revising Talmy's typological classification of complex events. In Hans C. Boas (ed.), Contrastive construction grammar, 201-235. Amsterdam \& Philadelphia: John Benjamins.

Cummins, Sarah. 1998. Le mouvement directionnel dans une perspective d'analyse monosémique. Langues et Linguistique 24. 47-66.

Davies, Mark 2002-. Corpus del Español (CE): 100 million words, 1200s-1900s. Available online at http://www.corpusdelespanol.org.

De Swart, Henriëtte 2000. Tense, aspect and coercion in a cross-linguistic perspective. Proceedings of the Berkeley Formal Grammar Conference, 1-20. Stanford, CA: CSLI Publications.

Demonte, Violeta. 1990. Transitividad, intransitividad y papeles temáticos. In Violeta Demonte \& Beatriz Garza Cuarón (eds.), Estudios de lingüística de España y México, 115-150. México: Colexio de México-UNAM.

Diessel, Holger. 2004. The acquisition of complex sentences. Cambridge: Cambridge University Press.

Diessel, Holger. 2007. Frequency effects in language acquisition, language use and diachronic change. New Ideas in Psychology 25. 108-127.

Diessel, Holger. 2013. Construction grammar and first language acquisition. In Graeme Trousdale \& Thomas Hoffmann (eds.), The Oxford handbook of construction Grammar, 347-364. Oxford: Oxford University Press.

Dini, Luca \& Vittorio Di Tomaso. 1995. Linking theory and lexical ambiguity: The case of Italian motion verbs. Quaderni del Laboratorio di Linguistica 9. 161-169.

Dowty, David. 1979. Word meaning and montague grammar. Dordrecht: Reidel.

Dowty, David. 1991. Thematic proto-roles and argument selection. Language 67(3). 547-619.

Dubinsky, Stanley. 1985. Oblique to direct object advancement in Japanese. Linguistic Analysis 15. 57-75. 
Fábregas, Antonio. 2007. The exhaustive lexicalisation principle. Nordlyd: Tromsø Working Papers on Language and Linguistics 34(2). 165-199. doi:10.7557/12.110.

Fillmore, Charles J. \& Paul Kay. 1999. Grammatical constructions and linguistic generalizations: The what's $X$ doing Y? construction. Language 75(1). 1-33.

Folli, Raffaella. 2008. Complex PPs in Italian. In Anna Asbury, Jakub Dotlacil, Berit Gehrke \& Rick Nouwen (eds.), Syntax and semantics of spatial P, 197-220. Amsterdam \& Philadelphia: John Benjamins.

Folli, Raffaella \& Gillian Ramchand. 2005. Prepositions and results in Italian and English: An analysis from event decomposition. In Henk Verkuyl, Henriëtte de Swart \& Angeliek van Hout (eds.), Perspectives on aspect, 81-105. Dordrecht: Kluwer.

García Miguel, José María. 1995. Transitividad y complementación preposicional en español (Verba, Anexo 40). Santiago de Compostela: Universidade de Santiago de Compostela.

Gehrke, Berit. 2008. Ps in motion: On the semantics and syntax of $P$ elements and motion events. Utrecht: Netherlands Graduate School of Linguistics (LOT).

Givón, Talmy. 1984. Syntax: A functional-typology introduction, vol. 1. Amsterdam \& Philadelphia: John Benjamins.

Givón, Talmy. 1993. English grammar: A function-based introduction, vol. 2. Amsterdam \& Philadelphia: John Benjamins.

Givón, Talmy. 1995. Functionalism and grammar. Amsterdam \& Philadelphia: John Benjamins.

Givón, Talmy. 2001 [1984]. Syntax: A functional-typology introduction, vol. 1. Amsterdam \& Philadelphia: John Benjamins.

Goldberg. 2013. Constructionist approaches. In Graeme Trousdale \& Thomas Hoffmann (eds.), Oxford handbook of construction grammar, 15-31. Oxford: Oxford University Press.

Goldberg, Adele E. 1995. Constructions: A construction grammar approach to argument structure. Chicago, IL: The University of Chicago Press.

Goldberg, Adele E. 2006. Constructions at work: The nature of generalization in language. Oxford: Oxford University Press.

Goldberg, Adele E. 2009a. The nature of generalization in language. Cognitive Linguistics 20. 93-128.

Goldberg, Adele E. 2009b. Constructions work. Cognitive Linguistics 20. 201-224.

Goldberg, Adele E. \& Ray Jackendoff. 2004. The English resultative as a family of constructions. Language 80. 532-568.

Gonzálvez-García, Francisco. 2009. The family of object-related depictives in English and Spanish: Towards a usage-based constructionist analysis. Language Sciences 31. 663-723.

Gonzálvez-García, Francisco \& Cristopher Butler. 2006. Mapping functional-cognitive space. Annual Review of Cognitive Linguistics 4. 39-96.

Gries, Stefan Th. 2012. Frequencies, probabilities, association measures in usage-/exemplarbased linguistics: Some necessary clarifications. Studies in Language 36(3). 477-510.

Gries, Stefan Th. 2015. More (old and new) misunderstandings of collostructional analysis: Schmid \& Küchenhoff (2013). Cognitive Linguistics 26(3). 505-536.

Gries, Stefan Th., Beate Hampe \& Doris Schönefeld. 2005. Converging evidence: Bringing together experimental and corpus data on the association of verbs and constructions. Cognitive Linguistics 16(4). 635-676.

Gropen, Jess, Steven Pinker, Michelle Hollander \& Richard Goldberg. 1991. Affectedness and direct objects: The role of lexical semantics in the acquisition of verb argument structure. Cognition 41(1-3). 153-195. 
Hernández Paricio, Francisco. 2004. Estructura léxico-conceptual y predicados de movimiento (acerca del predicado caer). In Enrique Serra \& Gerd Wotjak (eds.), Cognición y percepción lingüísticas (comunicaciones presentadas al VI Congreso Internacional de Lingüística Hispánica, Leipzig, 8-12 de octubre de 2003, volumen 3), 60-74. València \& Leipzig: Universitat de València \& Universität Leipzig.

Hilpert, Martin. 2008. Germanic future constructions: A usage-based approach to language change. Amsterdam \& Philadelphia: John Benjamins.

Hopper, Paul J. \& Sandra A. Thompson. 1980. Transitivity in grammar and discourse. Language 56(2). 251-299.

Israel, Michael. 1996. The way-constructions grow. In Adele Goldberg (ed.), Conceptual structure, discourse, and language, 217-230. Stanford, CA: Center for the Study of Language and Information.

Iwata, Seizi. 2008. Locative alternation: A lexical-constructional approach. Amsterdam \& Philadelphia: John Benjamins.

Jackendoff, Ray. 1983. Semantics and cognition. Cambridge, MA: MIT Press.

Jackendoff, Ray. 1990. Semantic structures. Cambridge, MA: MIT Press.

Jones, Michael A. 1996. Foundations of French syntax. Cambridge: Cambridge University Press.

Kemmer, Susanne \& Michael Barlow. 2000. Introduction: A usage-based conception of language. In Michael Barlow \& Susanne Kemmer (eds.), Usage-based models of grammar, vii-xxviii. Stanford, CA: Center for the Study of Language and Information.

Kittilä, Seppo. 2002. Remarks on the basic transitive sentence. Language Sciences 24. 107-130.

Kittilä, Seppo. 2011. Transitivity typology. In Jae Jung Song (ed.), The Oxford handbook of linguistic typology, 346-367. Oxford: Oxford University Press.

Knobel, Mark, Matthew Finkbeiner \& Alfonso Caramazza. 2008. The many places of frequency: Evidence for a novel locus of the lexical frequency effect in word production. Cognitive Neuropsychology 25(2). 256-286.

Kopecka, Anetta. 2009. L'expression du déplacement en français: L'interaction des facteurs sémantiques, aspectuels et pragmatiques dans la construction du sens spatial. Langages 173. 54-77.

Krifka, Manfred. 1992. Thematic relations as links between nominal reference and temporal constitution. In Ivan A. Sag \& Anna Szabolcsi (eds.), Lexical matters, 29-53. Stanford, CA: Center for the study of Language and Information.

Kulikov, Leonid. 2011. Voice typology. In Jae Jung Song (ed.), The Oxford handbook of linguistic typology, 368-398. Oxford: Oxford University Press.

Langacker, Ronald W. 1987. Foundations of cognitive grammar, vol. 1. Stanford, CA: Stanford University Press.

Langacker, Ronald W. 1988. A usage-based model. In Brygida Rudzke-Ostyn (ed.), Topics in cognitivel linguistics, 127-161. Amsterdam \& Philadelphia: John Benjamins.

Langacker, Ronald W. 1990. A usage-based model. In Ronald Langacker (ed.), Concept, image and symbol: The cognitive basis of grammar, 261-288. Berlin \& New York: Mouton de Gruyter.

Langacker, Ronald W. 1991. Foundations of cognitive grammar, vol. 2. Stanford, CA: Stanford University Press.

Langacker, Ronald W. 2000. A dynamic usage-based model. In Michael Barlow \& Susanne Kemmer (eds.), Usage-based models of language, 1-63. Stanford, CA: Center for the study of Language and Information. 
Langacker, Ronald W. 2009. Cognitive (Construction) Grammar. Cognitive Linguistics 20(1). 167-176.

Lazard, Gilbert. 1998. Actancy. Berlin \& New York: Mouton de Gruyter.

Levin, Beth \& Malka Rappaport Hovav. 2019. Lexicalization patterns. In Robert Truswell (ed.), Oxford handbook of event structure, 395-425. Oxford: Oxford University Press.

Luraghi, Silvia. 2010. The extension of the transitive construction in Ancient Greek. Acta Linguistica Hafniensia 42(1). 60-74.

Martínez Vázquez, Montserrat. 2001. Delimited events in English and Spanish. Estudios Ingleses de la Universidad Complutense 9. 31-59.

Mateu, Jaume. 2008. On the l-syntax of directionality/resultativity: The case of Germanic preverbs. In Anna Asbury, Jakub Dotlacil, Berit Gehrke \& Rick Nouwen (eds.), Syntax and semantics of spatial P, 221-250. Amsterdam \& Philadelphia: John Benjamins.

Melis, Ludo. 2001. Les compléments nominaux des verbes de mouvement intransitifs et la constellation de l'objet. In Claude Buridant, George Kleiber \& Jean C. Pellat (eds.), Par monts et par vaux, itinéraires linguistiques et grammaticaux, 243-258. Louvain \& Paris: Peeters.

Michaelis, Laura A. 2003a. Word meaning, sentence meaning and constructional meaning. In Hubert Cuyckens, René Dirven \& John R. Taylor (eds.), Cognitive approaches to lexical semantics, 163-210. Berlin \& New York: Mouton de Gruyter.

Michaelis, Laura A. 2003b. Headless constructions and coercion by construction. In Elaine J. Francis \& Laura A. Michaelis (eds.), Mismatch: Form-function incongruity and the architecture of grammar, 259-310. Stanford, CA: CSLI Publications.

Michaelis, Laura A. 2004. Type shifting in construction grammar: An integrated approach to aspectual coercion. Cognitive Linguistics 15. 1-67.

Michaelis, Laura A. 2005. Entity and event coercion in a symbolic theory of syntax. In Jan-Ola Østman \& Miriam Fried (eds.), Construction Grammar(s): Cognitive grounding and theoretical extensions (Constructional Approaches to Language 3), 45-88. Amsterdam \& Philadelphia: John Benjamins.

Moens, Marc \& Mark Steedman. 1988. Temporal ontology and temporal reference. Computational Linguistics 14(2). 15-28.

Morimoto, Yoko. 2001. Los verbos de movimiento. Madrid: Visor.

Muehleisen, Victoria \& Mutsumi Imai. 1997. Transitivity and the incorporation of Ground information in Japanese path verbs. In Kee Dong Lee, Eve Sweetwer \& Marjolijn Verspoor (eds.), Lexical and syntactic constructions and the constructions of meaning, 329-346. Amsterdam \& Philadelphia: John Benjamins.

Næss, Åshild. 2007. Prototypical transitivity. Amsterdam \& Philadelphia: John Benjamins. Narasimhan, Bhuvana. 2003. Motion events and the lexicon: A case study of Hindi. Lingua 113(2). 123-160.

Nemoto, Noriko. 2005. Verbal polysemy and frame semantics in Construction Grammar: Some observations about the locative alternation. In Miriam Fried \& Hans C. Boas (eds.), Grammatical constructions: Back to the roots, 119-138. Amsterdam \& Philadelphia: John Benjamins.

Oliveira, Aparecida de Araújo. 2016. Telicity and verb meaning in the choice of transitive or intransitive motion constructions in Brazilian Portuguese. Paper presented at the International Conference on Construction Grammar (ICCG9), University of Juiz de Fora, Brazil, 5-7 October. 
Panther, Klaus-Uwe \& Linda L. Thornburg. 1999. Coercion and metonymy: The interaction of constructional and lexical meaning. In Barbara Lewandowska Tomaszczyk (ed.), Cognitive perspectives on language, 37-51. Frankfurt am Main: Peter Lang.

Pedersen, Johan. 2013. The way-construction and cross-linguistic variation in syntax. Implications for typological theory. In Carita Paradis, Jean Hudson \& Ulf Magnusson (eds.), The construal of spatial meaning, windows into conceptual space, 236-262. 0xford: Oxford University Press.

Pedersen, Johan. 2014. Variable type framing in Spanish constructions of directed motion. In Hans C. Boas \& Francisco Gonzálvez García (eds.), Romance perspectives on construction grammar (Constructional approaches to language 15), 269-304. Amsterdam \& Philadelphia: John Benjamins.

Pedersen, Johan. 2016. Spanish constructions of directed motion - A quantitative study: Typological variation and framing strategy. In Jiyoung Yoon \& Stefan Th. Gries (eds.), Corpus-based approaches to construction grammar (Constructional approaches to language 19). 105-144. Amsterdam \& Philadelphia: John Benjamins.

Pustejovsky, James. 1991. The generative lexicon. Computational Linguistics 17(4). 409-441.

Pustejovsky, James. 1995. Linguistic Constraints on type coercion. In Patrick Saint-Dizier \& Evelyne Viegas (eds.), Computational lexical semantics, 71-97. Cambridge: Cambridge University Press.

Rice, Sally 1987. Participants and non-participants: Toward a cognitive model of transitivity. San Diego: University of California San Diego dissertation.

Ruiz de Mendoza, Francisco. 2013. Meaning construction, meaning interpretation, and formal expression in the Lexical Constructional Model. In Brian Nolan \& Elke Diedrichsen (eds.), Linking constructions into functional linguistics: The role of constructions in grammar, 231-270. Amsterdam \& Philadelphia: John Benjamins.

Ruiz de Mendoza, Francisco \& Ricardo Mairal-Usón. 2008. Levels of description and constraining factors in meaning construction: An introduction to the Lexical constructional model. Folia Linguistica 42(2). 355-400.

Sarda, Laure 1999. Contribution à l'étude de la sémantique de l'espace et du temps: analyse des verbes de déplacement transitifs directs du français. Toulouse: University of Toulouse le Mirail dissertation.

Sarda, Laure. 2000. Semantics of French direct transitive motion verbs. In Eniko Németh (ed.), Cognition in language use (Selected Papers from the Seventh International Pragmatics Conference, vol 1), 388-404. Antwerp: International Pragmatics Association.

Schmid, Hans-Jörg. 2007. Non-compositionality and emergent meaning of lexico-grammatical chunks: A corpus study of noun phrases with sentential complements as constructions. Zeitschri?t für Anglistik und Amerikanistik 3(3). 313-340.

Slobin, Dan I. 2004. The many ways to search for a frog: Linguistic typology and the expression of motion events. In Sven Strömquist \& Ludo Verhoeven (eds.), Relating events in narrative: Typological perspectives, 219-257. Mahwah, NJ: Lawrence Erlbaum.

Snyder, William. 2001. On the nature of syntactic variation: Evidence from complex predicates and complex word-formation. Language 77(2). 324-342.

Son, Minjeong. 2007. Directionality and resultativity: The cross-linguistic correlation revisited. Nordlyd: Tromsø Working Papers in Linguistics 34(2). 126-164. doi:10.7557/12.116.

Stefanowitsch, Anatol \& Stefan Th. Gries. 2003. Collostructions: Investigating the interaction beween words and constructions. International Journal of Corpus Linguistics 8(2). 209-243. 
Talmy, Leonard. 1985. Lexicalization patterns: Semantic structure in lexical forms. In Timothy Shopen (ed.), Language typology and syntactic description, vol. 3: Grammatical categories and the lexicon, 57-149. Cambridge: Cambridge University Press.

Talmy, Leonard 1991. Path to realization: A typology of event conflation. Proceedings of the Seventeenth Annual Berkeley Linguistics Society, 480-519. Berkeley, CA: Berkeley Linguistics Society.

Talmy, Leonard. 2000. Toward a cognitive semantics, vol. 1 and 2. Cambridge, MA: MIT Press. Taylor, John R. 2003. Cognitive grammar. Oxford: Oxford University Press.

Tenny, Carol. 1995. How motion verbs are special: The interaction of semantic and pragmatic information in aspectual verb meanings. Pragmatics \& Cognition 3(1). 31-73.

Tomasello, Michael. 1992. First verbs: A case study of early grammatical development. Cambridge: Cambridge University Press.

Tomasello, Michael. 2000. Do young children have adult syntactic competence? Cognition 74. 209-253.

Tomasello, Michael. 2002. The evolution of grammar in early child language. In Talmy Givón \& Bertram F. Malle (eds.), The evolution of language out of pre-language, 309-328. Amsterdam \& Philadelphia: John Benjamins.

Tomasello, Michael. 2003. Constructing a language: A usage-based theory of language acquisition. Cambridge, MA: Harvard University Press.

Traugott, Elizabeth C. 2007. The concepts of constructional mismatch and type-shifting from the perspective of grammaticalization. Cognitive Linguistics 18. 523-557.

Vendler, Zeno. 1967. Verbs and times. In Zeno Vendler (ed.), Linguistics in philosophy, 97-121. Ithaca, NY: Cornell University Press.

Verhagen, Arie. 2002. From parts to wholes and back again. Cognitive Linguistics 13(4). 403-440.

Verhagen, Arie. 2011. Construal and Perspectivization. In Dirk Geeraerts \& Hubert Cuyckens (eds.), The Oxford handbook of cognitive linguistics, 48-81. Oxford: Oxford University Press.

Wiechmann, Daniel. 2008. On the computation of collostruction strength: Testing measures of association as expressions of lexical bias. Corpus Linguistics and Linguistic Theory 4(2). 253-290.

Yoon, Soyeon 2012. Constructions, semantic compatibility and coercion: An empirical usagebased approach. Houston, TX: Rice University dissertation.

Zubizarreta, Maria Luisa \& Eunjeong Oh. 2007. On the syntactic composition of manner and motion. Cambridge, MA: MIT Press. 